\title{
In vivo efficacy of endothelial growth medium stimulated mesenchymal stem cells derived from patients with critical limb ischemia
}

\author{
Rida Al-Rifai' , Philippe Nguyen ${ }^{1,2}$, Nicole Bouland ${ }^{3}$, Christine Terryn ${ }^{4}$, Lukshe Kanagaratnam5, Gaël Poitevin ${ }^{1}$, \\ Caroline François ${ }^{1}$, Catherine Boisson-Vidal| ${ }^{6,7}$, Marie-Antoinette Sevestre ${ }^{8}$ and Claire Tournois ${ }^{1,2^{*}}$ (D)
}

\begin{abstract}
Background: Cell therapy has been proposed for patients with critical limb ischemia (CLI). Autologous bone marrow derived cells (BMCs) have been mostly used, mesenchymal stem cells (MSCs) being an alternative. The aim of this study was to characterize two types of MSCs and evaluate their efficacy.

Methods: MSCs were obtained from CLI-patients BMCs. Stimulated- (S-) MSCs were cultured in endothelial growth medium. Cells were characterized by the expression of cell surface markers, the relative expression of 6 genes, the secretion of 10 cytokines and the ability to form vessel-like structures. The cell proangiogenic properties was analysed in vivo, in a hindlimb ischemia model. Perfusion of lower limbs and functional tests were assessed for 28 days after cell infusion. Muscle histological analysis (neoangiogenesis, arteriogenesis and muscle repair) was performed.
\end{abstract}

Results: S-MSCs can be obtained from CLI-patients BMCs. They do not express endothelial specific markers but can be distinguished from MSCs by their secretome. S-MSCs have the ability to form tube-like structures and, in vivo, to induce blood flow recovery. No amputation was observed in S-MSCs treated mice. Functional tests showed improvement in treated groups with a superiority of MSCs and S-MSCs. In muscles, CD31+ and aSMA+ labelling were the highest in S-MSCs treated mice. S-MSCs induced the highest muscle repair.

Conclusions: S-MSCs exert angiogenic potential probably mediated by a paracrine mechanism. Their administration is associated with flow recovery, limb salvage and muscle repair. The secretome from S-MSCs or secretome-derived products may have a strong potential in vessel regeneration and muscle repair.

Trial registration NCT00533104

Keywords: Angiogenesis, Cell therapy, Critical limb ischemia, Mesenchymal stem cells

\section{Background}

Critical limb ischemia (CLI) is the most severe form of atherosclerotic peripheral arterial disease (PAD). Due to the progression of vascular risk factors, PAD incidence is predicted to double by 2050 [1]. The management of patients is limited to surgical revascularization. However, around up to $30 \%$ of patients are not eligible for such procedures due to poor distal vascular bed. Therefore, these

\footnotetext{
*Correspondence: claire.tournois@univ-reims.fr

${ }^{1}$ EA-3801, SFR CAP-santé, Université de Reims Champagne-Ardenne,

51092 Reims Cedex, France

Full list of author information is available at the end of the article
}

"no-option" patients (NO-CLI) experience a high risk of major amputation [2] and are exposed to a high level of cardiovascular death [3].

In such context, cell therapy $(\mathrm{CT})$ has been proposed for NO-CLI patients to promote angiogenesis and improve tissue perfusion [4]. To date over 120 phase I/ II or III clinical trials have investigated a variety of cell therapies [5]. Recent meta-analysis [6] are in favor of a clinical improvement of treated patients but results remain divided $[7,8]$. In most cases, non-selected autologous bone marrow derived cells (BMCs) were used. They were obtained from elderly ill patients and 
exhibit low proangiogenic potential [9]. In most studies BMCs were not well characterized.

We recently published a multicenter clinical trial evaluating the effect of autologous BMCs versus placebo in CLI-patients [Bone Marrow Autograft in Limb Ischemia (BALI)]. This study was in favor of efficacy but the rate of amputation remained elevated in treated patients [10]. Inflammation was associated with poor outcome [11]. In order to improve our understanding, BMCs were extensively characterized and we observed a great variability in BMCs composition between patients [11].

BMCs contained mature and immature cells [hematopoietic stem cells (HSCs), endothelial progenitor cells]. Interestingly, they also contained a rare subset of mesenchymal stem cells (MSCs). These non-hematopoietic mononuclear cells reside in the bone marrow (BM) stroma [12]. MSCs can be obtained in adults from many tissues such as adipose tissue (ADSCs), peripheral blood, synovial membrane and dental pulp. Fetal/ neonatal tissues [e.g., umbilical cord blood, umbilical cord Wharton's jelly (WJ-MSCs), amniotic fluid, placenta] are also a potential source of MSCs [13]. Still, human BM remains the main source of MSCs. They show an extensive capacity of differentiation into osteoblasts, chondrocytes, adipocytes, astrocytes and skeletal muscle cells [14]. MSCs can migrate, proliferate in areas of ischemia and can promote regeneration of damaged tissues and reducing inflammation [15]. They may be good candidates for $\mathrm{CT}$ as they combine proangiogenic, anti-inflammatory and immunomodulatory properties [16].

CT protocols in CLI-generally require hundreds of millions of MSCs per treatment [17-19]. Therefore, in vitro cell expansion is needed. In autologous situation, the patient's age and clinical characteristics influence the culture efficiency [20]. Major efforts have been made to improve culture conditions and favor endothelial induction by adding supplements containing pro-angiogenic factors [vascular endothelial growth factor (VEGF), epidermal growth factor (EGF), fibroblast growth factor-2 (FGF2) and insulin-like growth factor-1 (IGF-1)] [21-27]. The so called "endothelial cell-specific growth medium" (EGM-2) improves the proliferation rate and may induce the acquisition of endothelial markers. These stimulatedMSCs (S-MSCs) can form functional blood vessels in collagen-plug implanted in mice [21] but have never been tested in a hind limb ischemia model (HLIM).

The purpose of this study was: (1) to evaluate the presence of MSCs in CLI-patients BMCs, (2) to analyze the phenotype of S-MSCs, and (3) to compare the effect of MSCs and S-MSCs in a murine HLIM in comparison with BMCs.

\section{Methods}

\section{Source and characterization of BMCs}

BMCs were obtained from CLI patients included in the BALI multicenter trial (trial number NCT00533104). The study protocol was approved by the French National Agency for Medicines and Health Products Safety and by an Institutional Review Board. As previously described [10], $500 \mathrm{~mL}$ of $\mathrm{BM}$ were collected under general anesthesia through multiple punctures of the posterior iliac crest. BMCs were isolated using a blood cell separator (Cobe Spectra, version 4, BM Processing Program, Gambro BCT, Lakewood, CO, USA) and concentrated to obtain a final volume of $40 \mathrm{~mL}$ ( $30 \mathrm{~mL}$ for autologous injection and $10 \mathrm{~mL}$ for control analyses and cryopreservation). BMCs were cryopreserved in liquid nitrogen in dimethyl sulfoxide as a cryoprotector.

The present study is as an ancillary study of BALI. BMCs were exclusively provided by the centers of Reims and Amiens (out of 9 centers) as they used similar methods of cell preparation, preservation and storage. Seven CLI-BMCs were selected regardless of patients' characteristics or clinical outcome.

BMCs were extensively characterized. For this, platelets (PLTs) and nucleated cells counts were performed with an Advia 2120 automated counter (Siemens, Health care SAS, Saint-Denis, France). Cell morphology was observed after cytocentrifugation and May Grünwald Giemsa staining (Fig. 2a). CD34+ stem cell analysis was performed by flow cytometry (FC) according to the ISHAGE (International Society of Hematotherapy and Graft Engineering) reference method using Stem-Kit reagents (Beckman Coulter, Villepinte, France). Samples were analyzed on a Navios flow cytometer (Beckman Coulter). The MesenCult Proliferation Kit (Stemcell Technologies, Grenoble, France) was used for the fibroblast colony-forming units (CFU-F) assay.

\section{Isolation of BM-MSCs and cell culture}

MSCs were obtained from 7 CLI cryopreserved BMCs. After thawing, cells were counted, and viability was evaluated. MSCs were selected by their capacity to adhere to uncoated plastic plates, cultured and expanded in a CFU-F medium (MesenCult ${ }^{\mathrm{TM}}$ Proliferation Kit, Stemcell Technologies) supplemented with $1 \%$ penicillin-streptomycin-amphotericin (Antibiotic-Antimycotic 100X, Gibco by Life Technologies, Illkirch, France). Cells were cultured in a humidified incubator at $37{ }^{\circ} \mathrm{C}$ under a $5 \%$ $\mathrm{CO}_{2}$ atmosphere. The culture was maintained through 28 days (Fig. 1a).

S-MSCs were obtained from 7 CLI-MSCs after trypsinization at day 14, and subsequent culture during another period of 14 days in a Endothelial growth medium (EGM)-2 comprised endothelial basal medium (EBM)-2 


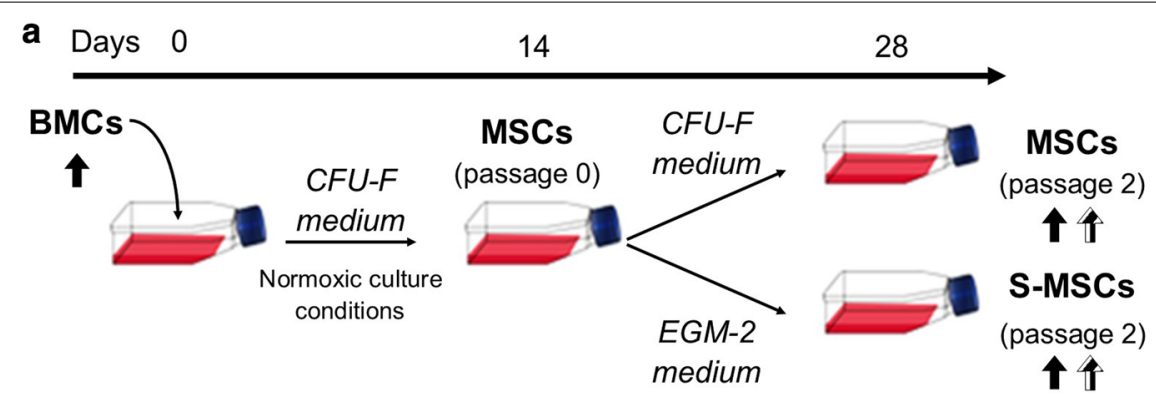

$\uparrow$ Cells characterization (Transcriptome, immunophenotype, secretome and Matrigel assay)

$\uparrow$ Cells injection (HLIM)

b

HO: HLIM
Days

Fig. 1 Study design. a BMCs were obtained from 7 CLI patients. MSCs were selected and expanded in a CFU-F medium for 28 days $(n=7)$. Stimulated MSCs were cultured in EGM-2 medium for 14 days $(n=7)$. b Hindlimb ischemia was induced by femoral artery ligation in Nude mice. Cells (BMCs, MSCs, S-MSCs) or vehicle were injected in the gastrocnemius. Hindlimb perfusion, Necrose detection and functional tests were performed during 28 days. At day 28 muscles were harvested for biological analysis

supplemented with SingleQuots Bulle-kit (Lonza, Basel, Switzerland) (0.5 ng/mL human VEGF, $5 \mathrm{ng} / \mathrm{mL}$ human EGF, $10 \mathrm{ng} / \mathrm{mL}$ human FGF2, $20 \mathrm{ng} / \mathrm{mL}$ long R3-insulin-like growth factor-1, $22.5 \mu \mathrm{g} / \mathrm{mL}$ heparin, $1 \mu \mathrm{g} / \mathrm{mL}$ ascorbic acid, $0.2 \mu \mathrm{g} / \mathrm{mL}$ hydrocortisone) supplemented with $1 \%$ penicillin-streptomycin-amphotericin (Antibiotic-Antimycotic 100X, Gibco). Cells were cultured in a humidified incubator at $37{ }^{\circ} \mathrm{C}$ under a $5 \% \mathrm{CO}_{2}$ atmosphere (Fig. 1a).

Culture media were changed every 3 or 4 days. MSCs and S-MSCs were observed in phase contrast microscopy (Olympus, Plateforme en Imagerie Cellulaire et Tissulaire PICT). Before injection, cells were washed twice in Phosphate Buffer Saline (PBS) (ET330, Euromedex, Souffelweyersheim, France), then counted. Viability was determined by Trypan blue and was above $90 \pm 6 \%$. Cells were resuspended in PBS.

\section{Characterization of MSCs and S-MSCs Transcriptomic characterization of MSCs, S-MSCS and $c b$-ECFCs by simultaneous real-time qPCR reactions} Gene expression analysis was performed at day 28 , on both MSCs $(n=7)$ and S-MSCs $(n=7)$. Cord blood endothelial colony-forming cells (cb-ECFCs, $\mathrm{n}=5$ ) were used as control. Isolation and characterization of cbECFC were performed as previously described [28]. Total RNA was extracted from $5 \times 10^{6}$ cells, using the RNeasy Mini kit (Qiagen, Courtaboeuf, France). RNA was treated to eliminate any DNA contamination (Qiagen) and the quality of mRNA was assessed using the Experion automated electrophoresis system (Bio-Rad, Marnes La Coquette, France). Complementary DNA was synthesized using the high-capacity cDNA reverse transcriptase (RT) kit with RNase inhibitor ( $\mathrm{RT}^{2}$ HT First Strand Kit, Qiagen). PCR primers targeting von Willebrand factor (vWF)(NM_000552.3), platelet endothelial cell adhesion molecule 1 (PECAM1)(NM_000442.4), vascular endothelial growth factor receptor 2 (VEGF R2 or KDR) (NM_002253.2), Ve-Cadherin (CDH5)(NM_001795.3), CXC motif receptor 4 (CXCR4)(NM_003467.2), vascular cell adhesion molecule 1 (VCAM1)(NM_001078.3), beta-2 microglobulin (B2M)(NM_004048), hypoxantine phosphoribosyltransferase-1 (HPRT1) (NM_000194) and glyceraldehyde-3-phosphate-dehydrogenase (GAPDH) (NM_002046) were obtained from Qiagen (RNA QC PCR Array Qiagen). B2 M, HPRT1 and GAPDH were 
used as housekeeping genes. Conventional PCR was performed under standard conditions $\left(\mathrm{RT}^{2}\right.$ SYBR Green ROX qPCR, Qiagen) and analyzed on the ABI 7500 FAST-Real Time PCR System (Thermo Fisher Scientific, Courtaboeuf, France). Assays were systematically run in duplicate for each type of cells and for internal controls (human genomic DNA contamination, reverse transcription control and positive PCR control). The mRNA levels of vWF, PECAM1, VEGF R2, Ve-Cadherin, CXCR4 and VCAM1 were normalized to housekeeping genes using the $2^{-\Delta \mathrm{Ct}}$ method $\left(=2^{-[\mathrm{Ct}(\text { target })-\mathrm{Ct}(\text { housekeeping gene })]}\right)$.

\section{Flow cytometry analysis}

A four-color FC analysis was performed on FC500 analyzer (Beckman Coulter) to characterize MSCs and S-MSCs at day 28: FITC-conjugated CD105 (endoglin), CD31 (PECAM1) antibodies and PE-conjugated CD90 (Thy-1), CD140a (Platelet-derived growth factor receptor alpha, PDGF RA), CD140b (Platelet-derived growth factor receptor beta, PDGF RB), CD144 (Ve-Cadherin, CDH5), VEGF R1 (Vascular endothelial growth factor receptor 1, FLT1) antibodies and PE-Cy5-conjugated HLA-DR (human leukocyte antigen-D related), CD34, CD45, CD11b (integrin alpha M), CD146 (Melanoma adhesion molecule, MCAM), CD184 (CXCR4), CD106 (VCAM1) antibodies and PE-Cy7 conjugated CD73 (5' nucleotidase) and VEGF R2 (KDR, CD309) antibodies. Mouse anti-Human CD105, CD90, CD73, HLADR, CD140a, CD31, CD184, CD106 were obtained from BD Biosciences (Le Pont de Claix, France), CD34, CD45, CD11b, CD146, VEGFR2 from Beckman Coulter, CD140a, VEGFR1 from R\&D Systems Inc (Minneapolis, USA) and CD144 from Santa-Cruz Biotechnology inc SCBT (Dallas, USA). The isotype-matched mouse IgG1FITC, IgG1-PE, IgG1-PCy5 and IgG1-PCy7 were used as negative controls. Acquisition and processing data from 7,000 events were analysed using Kaluza software.

\section{Cell secretome}

Cell secretome was characterized by the quantification of growth factors productions and by their capacity to form tube-like structures.

\section{Preparation of MSCs- and S-MSCs-derived conditioned medium}

Culture media (CFU-F and EGM-2) had been changed at day 24. Aliquots of the CFU-F and EGM-2 media free of cells were placed in a humidified incubator at $37^{\circ} \mathrm{C}$ under a $5 \% \mathrm{CO}_{2}$ atmosphere during 4 days. MSCs $(\mathrm{n}=7)$ and S-MSCs $(n=7)$ culture supernates and cell-free media (CFU-F and EGM-2) were recovered at day 28, centrifuged at $300 \mathrm{~g}$ for $5 \mathrm{~min}$, filtered through a $0.22 \mu \mathrm{m}$ and were then aliquoted and stored frozen at $-40{ }^{\circ} \mathrm{C}$ until use.

\section{Growth factors assays}

A set of ten growth factors [VEGF-A, EGF, FGF2, IGF1, Angiopoietin-1 (Angio-1), Interleukin-6 (IL-6), HGF, Platelet-derived growth factor alpha polypeptide (PDGFAA), Leukemia-inhibitory Factor (LIF), Chemokine CXC motif Ligand 12 (CXCL12 or Stromal-cell-derived factor-1, SDF-1)] was measured in the MSCs and S-MSCs culture supernates at day 28. Quantitative determination of IGF-1 concentrations was performed using the Quantikine ELISA kit (R\&D Systems Inc). The 9-plex LEGENDplex panel is a bead-based multiplex assay panel, using fluorescence-encoded beads suitable for use on LSRFortessa (BD Biosciences). This panel allows the simultaneous quantification of 9 human cytokines (VEGF-A, EGF, FGF2, Angio-1, IL-6, HGF, PDGF-AA, LIF, CXCL12) (BioLegend Ozyme, Saint Quentin en Yvelines, France) (Plateau technique de Cytometrie en flux URCACyt). The Bradford Protein assay (Quick Start ${ }^{\mathrm{TM}}$ Bradford $1 \times$ Dye Reagent, Bio-Rad) was used to measure protein quantification in MSCs and S-MSCs culture supernates and in 2 media (CFU-F and EGM-2).

\section{Tube formation assay}

In order to assess the angiogenic effect of culture supernates, an in vitro assay was performed evaluating tubule formation from HMEC-1 endothelial cell line (Dermal microvascular endothelium, ATCC CRL-3243) [29]. HMEC-1 cells (8000 cells/well) were suspended in Endothelial Cell Basal medium MV $(\mathrm{n}=3)(10 \mathrm{ng} / \mathrm{mL}$ EGF, $1 \mu \mathrm{g} / \mathrm{mL}$ hydrocortisone, $10 \mathrm{mM}$ Glutamine, and $10 \%$ FBS) (PromoCell, Heidelberg, Germany), or in cellfree media [CFU-F $(n=3)$, or EGM-2 $(n=3)]$ or in MSCs culture supernates (obtained from 5 CLI-MSCs, $\mathrm{n}=2$ each group), or in S-MSCs culture supernates (obtained from 5 CLI-S-MSCs, $\mathrm{n}=2$ each group), laid upon Matrigel (BD Biosciences, Le Pont de Claix, France) cast in IBIDI micro wells $(81,501, \mu$-Slide Angiogenesis, Biovalley), and allowed to form tubules for $24 \mathrm{~h}$ under normoxic conditions. Slides were observed during $24 \mathrm{~h}$ with a videomicroscope (Axiovert, $200 \mathrm{M}$, Zeiss, Germany) piloted by Software Metamorph (Roper Scientific). Pictures were catched each 15 min (coolsnap HQ, Roper Scientific, France). The capillary-like tubes were appreciated at 3:30 $\mathrm{h}$ by the quantification of the loops number and total tube length using the ImageJ software and Neuron-J plug in tool.

\section{Cell functional assay: in vitro tube formation assay}

Capillary-like tube formation was evaluated in a Matrigel (BD Biosciences) matrix. A volume of $10 \mu \mathrm{L}$ of gel was 
deposited on the uncoated slide (81,501, $\mu$-Slide Angiogenesis, Biovalley). After $30 \mathrm{~min}$ at $37{ }^{\circ} \mathrm{C}$, a gel was formed and $10^{4}$ cells (MSCs, S-MSCs, MRC and cbECFC) were deposited. The extend of the network of the capillary-like tubes was appreciated at the time of maximal network (as indicated on Additional file 1: Figure S1) by the quantification of the loops number using the ImageJ software and Neuron-J plug in tool. MRC5 fibroblasts cells line (ATCC CCL-171; RD-Biotech, Besançon, France) was used as negative control. cb-ECFC were used as positive control.

\section{Animal study \\ Study design}

The aim of the study was to evaluate the efficacy of BMCs, MSCs and S-MSCs from CLI patients in comparison with vehicle in a murine HLIM (Fig. 1b). BALB/c Nude mice were included in the study. Hindlimb perfusion and functional tests were assessed at baseline (day1). At day 0 hindlimb ischemia was induced after left common femoral artery ligation. Blood flow of the lower limbs was performed postoperatively. Viable cells [BMCs or MSCs or S-MSCs) or vehicle (PBS)] were injected in the left gastrocnemius muscle $4 \mathrm{~h}$ after ischemia induction. Blood flow measurement was considered as primary endpoint whereas necrosis detection and functional tests (static and dynamic) were considered as secondary endpoints. They were evaluated at days $1,3,5,7,10,15,20$ and 28 postoperatively. At day 28 gastrocnemius and semimembranosus muscles were harvested for immunohistological analyses (Fig. 1b).

\section{Murine hindlimb ischemia model and cell transplantation}

One hundred and thirty-five male BALB/c Nude mice (Charles River Laboratories, l'Arbresle, France), 11 weeks of age were used for all experiments. They had access to water and food ad libitum. Hindlimb ischemia was induced after the surgical left common femoral artery ligation [30]. Animals were placed on a $38^{\circ} \mathrm{C}$ heating pad and anesthetized by continuous inhalation of isoflurane (5\% in induction and 2\% during the intervention). Exposure was obtained by performing an incision in the skin overlying the high portion of the left hindlimb next to the inguinal ligament. The common left femoral artery was ligated with a non-absorbable 6.0 silk thread. Then the skin was closed with absorbable sutures. Buprenorphine was administered as analgesic $(0.05 \mathrm{mg} / \mathrm{kg}$ twice a day for 3 days). Under anesthesia, mice were transplanted in their left gastrocnemius $4 \mathrm{~h}$ after surgery with $30 \mu \mathrm{L}$ of PBS ( $\mathrm{n}=20$ mice) or with $30 \mu \mathrm{L}$ of $5 \times 10^{5}$ BMCs $(\mathrm{n}=40$ mice and approximately 6 per condition) or of $5 \times 10^{5}$ MSCs $(n=35$ mice and approximately 6 per condition) or of $5 \times 10^{5}$ S-MSCs $(\mathrm{n}=40$ mice and approximately
6 per condition). The quantity of injected cells $\left(5 \times 10^{5}\right)$ can be considered as low in comparison with similar previously published studies [31-33]. A 30-gauge needle was used for the unique intramuscular injection.

\section{Blood flow analysis}

Perfusion of lower limbs was assessed with PeriCam ${ }^{\circledR}$ perfusion imaging (PeriCam ${ }^{\circledR}$ PSI, Perimed, Craponne, France) at baseline and for 28 days after ligation. The Pericam perfusion imaging was able to quantify the blood flow in the microcirculation (arterioles, capillaries and veins) and the laser speckle contrast analysis (LASCA) facilitated high resolution and real-time visualization. Measures were taken under anesthesia with isoflurane and on a $38{ }^{\circ} \mathrm{C}$ heating pad. Low or no blood perfusion was displayed as dark blue, whereas the highest perfusion was displayed as red. After blood flow was scanned during $30 \mathrm{~s}$, stored records were analyzed with PimSoft ${ }^{\circledR}$ software and the average flows of ischemic and nonischemic limbs were quantified. Ratios of the ischemic (left)/normal (right) limb blood flow were used to express the results. The mean and the standard deviation were used per group.

\section{Clinical recovery}

Necrosis detection Limb ischemia was assessed with the daily observation of mouse limbs searching for nail, toe, foot and leg necrosis or amputation.

Two functional tests (static and dynamic) were used to quantify post-ligature clinical improvement:

- Static test: After surgical ligation, ischemic mouse paw retracted. Interdigital spacing (IDS) between the first and the 5th toe was measured using Image J software. For this, the mouse was placed in a transparent container to visualize from the bottom normal and ischemic paws. Measures were taken at day-1 (baseline), 1, 3, 5, 7, 10, 14, 20 and 28 post surgery. Results were expressed as a ratio of IDS ischemic/ control paw. Clinical improvement was testified by the gradual recovery of IDS.

- Dynamic test: A semi quantitative assessment of impaired use of ischemic limb was performed. Mice progressed in a transparent corridor to evaluate their walking. The functional scoring was adapted from Tarlov's [31]: score 0: the mouse does not use the paw-score 1: the mouse can rely on the left pawscore 2: the mouse can use its left paw but claudicates-score 3: normal walking. Measures were taken at day-1 (baseline), 1, 3, 5, 7, 10, 14, 20 and 28 post surgery. 
The mean and the standard deviation were used per group.

\section{Tissue preparation and immunohistological analysis}

The gastrocnemius and the semimembranosus muscles [30] right and left of each mouse were harvested at day 28. The semimembranosus muscle is localized close to the ligation upstream from the cell infusion site. For each condition, the muscles were frozen for immunofluorescence assay or fixed in formalin $10 \%$ for hematoxylin eosin (HE) staining.

For immunofluorescence, tissues were embedded in Optimal Cutting temperature (OCT) compound (F/ KMA-0100-00A, MM France, Francheville, France) and frozen in liquid nitrogen. Frozen sections of $6-\mu \mathrm{m}$ thickness were mounted on superfrost slides. Sequentially, slides were fixed in cold acetone for $20 \mathrm{~min}$, blocked with normal donkey serum (S30, Merck Millipore, St-Quentin-en-Yvelines, France) for $1 \mathrm{~h}$ at room temperature and incubated with primary antibody at $4{ }^{\circ} \mathrm{C}$ overnight. After washing three times with PBS, slides were incubated with secondary antibody during $1 \mathrm{~h}$ at room temperature. The vessels were visualized by immunofluorescent staining with a first anti-CD31 antibody (ab28364, abcam, Cambridge, United Kingdom) and a second anti alpha-smooth muscle actin antibody ( $\alpha$ SMA) (ab150129, abcam). Secondary fluorochrome-coupled antibodies were used (Alexa Fluor ${ }^{\circledR}$ 568, ab175470, abcam) and (Alexa Fluor $^{\circledR} 488$, ab21027, abcam). Slides were observed on an inverted fluorescence microscope $(20 \times$ magnification Axio Observer Z1, Zeiss Microscopy) piloted by Metamorph Software (Roper Scientific). Capillaries and arterioles were counted in 5 representative fields from 3 tissue sections for each muscle using ImageJ software. The amount of ischemia-induced angiogenesis and arteriogenesis were compared with the non-ischemic muscle. Macrophage infiltration were visualized by the same protocol using an anti-CD68 antibody (ab125212, abcam).

The fixed gastrocnemius and semimembranosus muscles were embedded in paraffin and stained with HE. We determine the percentage of muscle fibers with a central nucleus. Indeed, these muscle fibers specifically indicate muscle regeneration [34, 35]. For this, five fields were counted in the central region of the largest cross area of gastrocnemius muscle sections. The results were expressed as a ratio left muscle/right muscle. All results were expressed as mean and standard deviation per group.

\section{Real time quantitative polymerase chain reaction ( $q P C R$ )}

Real time qPCR was performed on right and left harvested gastrocnemius muscles of 4 mice (1 mouse for each group: vehicle, BMCs, MSCs and S-MSCs) at day 28 in order to detect human DNA. The DNA was extracted from the muscles with a DNeasy Blood and Tissue kit (69504, Qiagen) according to the manufacturer's instructions. Human DNA $(\mathrm{n}=2)$ was used as positive control. Gastrocnemius muscles of vehicle group and non-ischemic controlateral muscles were used as negative control. The qPCR was performed for human Factor V gene (TaqMan SNP genotyping assay, C_11975250_10, Thermo Fisher Scientific) and with a TaqMan universal PCR master mix (4324018, Thermo Fisher Scientific). We checked that human Factor V primers did not hybridize with mouse DNA using BLAST ${ }^{\circledR}$. Each DNA was analyzed thrice. The limit of detection of PCR was defined by a threshold cycle $(\mathrm{Ct})>35$.

\section{Statistical analyses}

Quantitative variables were expressed as mean and standard deviation per group or as median (Med) and range $[\mathrm{min}-\max ]$ or Box and Whiskers plots (Medcalc version 7.3 software, https://www.medcalc.org/). MannWhitney Tests were used to compare differences between groups at day 28. Wilcoxon Tests were used to compare differences between days in the same group $\left(\right.$ Statview $\left.^{\circledR}\right)$. A value of $\mathrm{p}<0.05$ was considered statistically significant. For blood flow analysis, a mixed effect model was performed to assess the relationship between the ischemic/ normal limb ratio and treatment group, the time of the measure, adjusted on the value of the ratio at day-1 (baseline value). Bonferroni method was used for multiple comparisons adjustments. The overall survival limb rates were estimated by the Kaplan-Meier method. Difference between survival curves for each experimental group was performed using the log rank test $\left(\mathrm{GraphPad}^{\circledR}\right)$.

\section{Results}

\section{Patient and BMCs characteristics}

BMCs were obtained from 7 different patients presenting with CLI and candidates for CT. Patients were representative of the NO-CLI population in terms of age, associated cardiovascular risk factors, and current medications (Table 1). The severity of the disease was appreciated from percutaneous tissue oxygen pressure $\left(\mathrm{TcPO}_{2}\right)$ and the presence of ulcers.

BMCs were characterized by cell counting and differential presented in Figs. 2a, 3a and Table 1. HSCs were quantified in BMCs by FC: $3.66 \% \pm 1 \%$ (Fig. 3a). MSCs were quantified in BMCs by a clonogenic assay (CFU-F): $39 \pm 16$ MSCs of 1 million nucleated cells (Table 1 ).

Clinical outcome after 6 and 12 months is presented in Table 1. 
Table 1 Patient characteristics

\begin{tabular}{|c|c|c|c|c|c|c|c|}
\hline & 1 & 2 & 3 & 4 & 5 & 6 & 7 \\
\hline \multicolumn{8}{|l|}{ Patients characteristics } \\
\hline Age (years) & 74 & 57 & 52 & 57 & 74 & 62 & 42 \\
\hline Gender (M: male; F: female) & M & M & M & M & $\mathrm{F}$ & M & M \\
\hline BMI $\left(\mathrm{kg} / \mathrm{m}^{2}\right)$ & 27 & 25 & 26 & 32 & 20 & 22 & 21 \\
\hline Smoker & No & Past & Past & Past & No & Past & Current \\
\hline Arterial hypertension & Yes & Yes & No & No & No & Yes & No \\
\hline Hyperlipidemia & Yes & No & Yes & No & Yes & No & No \\
\hline Diabetes mellitus & Yes & No & Yes & No & No & No & No \\
\hline \multicolumn{8}{|l|}{ Disease characteristics } \\
\hline $\mathrm{TcPO}_{2}(\mathrm{mmHg})$ & 26 & 30 & 64 & 35 & 45 & 1 & 7 \\
\hline Presence of ulcers & No & No & Yes & No & No & No & No \\
\hline Cardioprotective drugs use $\mathrm{a}^{\mathrm{a}}$ & AT, ACEI & AT, ACEI, S & AT, ACEI, S & AT, ACEI, S & AT & AT, S & AT, S \\
\hline \multicolumn{8}{|l|}{ BMC characterization } \\
\hline PLTs (G/L) & 746 & 740 & 478 & 590 & 384 & 1296 & 1118 \\
\hline Total nucleated cells $(\mathrm{G} / \mathrm{L})$ : & 47 & 60 & 38 & 48 & 50 & 76 & 71 \\
\hline \multicolumn{8}{|l|}{ Total MNCs } \\
\hline Lymphocytes (\%) & 46 & 47 & 39 & 41 & 48 & 46 & 54 \\
\hline Monocytes (\%) & 18 & 12 & 28 & 18 & 19 & 14 & 13 \\
\hline Erythroblasts and other cells $(\%)^{b}$ & 10.5 & 14.3 & 10.4 & 19.8 & 12.7 & 13.2 & 14.5 \\
\hline Mature granulocytes (\%) & 23 & 23 & 18 & 16 & 17 & 23 & 16 \\
\hline HSCs (CD34+ cells) (\%) & 2.5 & 3.7 & 4.6 & 5.2 & 3.3 & 3.8 & 2.5 \\
\hline $\mathrm{MSCs}^{c}$ & 42 & 38 & 34 & 58 & 28 & 12 & 60 \\
\hline Placebo or BMCs group & BMCs & BMCs & Placebo & Placebo & BMCs & BMCs & Placebo \\
\hline Clinical outcome at 6 months & $\emptyset$ & $\emptyset$ & $\emptyset$ & $\emptyset$ & $\emptyset$ & $\begin{array}{l}\text { Revascularization } \\
\text { at day } 126\end{array}$ & $\begin{array}{l}\text { Major ampu- } \\
\text { tation at day } \\
114\end{array}$ \\
\hline Clinical outcome at 12 months & $\begin{array}{l}\text { Revascularization } \\
\text { at day } 332\end{array}$ & $\emptyset$ & $\emptyset$ & $\emptyset$ & $\emptyset$ & & \\
\hline
\end{tabular}

Quantitative variables are expressed as median or absolute value. Biologic markers measured in 7 NO-CLI patients on day 0 (baseline) before CT

Ø: Patient alive without any major amputation

a Cardioprotective drugs use: antiplatelet therapy (AT), statins (S), angiotensin-converting enzyme inhibitor (ACEI)

b Other cells: blasts, immature granulocytes and plasma cells

c CFU-F number $/ 1 \times 10^{6}$ nucleated cells

\section{MSCs and S-MSCs in vitro characterization Cells morphology}

Human BM derived MSCs show plastic adherent properties and have fibroblast-like morphology seen under phase contrast microscope (Fig. 2b). S-MSCs were maintained in EGM-2 medium from subculture 0 to 2 during 14 days. S-MSCs presented similar fibroblast-like morphology (Fig. 2c). The S-MSCs' doubling time was significantly shorter in comparison with MSCs (respectively $4.6 \pm 1.6$ versus $7.3 \pm 1.8$ days, $\mathrm{p}<0.01)$.

\section{Transcriptomic profile}

In order to differentiate S-MSCs from MSCs, we determined the transcriptomic profile of both cells. For this, the expression of endothelial-lineage genes (vWF, PECAM1, VEGF R2, Ve-Cadherin, CXCR4 and VCAM1) was examined in MSCs and S-MSCs at day 28 (Fig. 2d). cb-ECFCs was used as a endothelial cells (ECs)-control. A set of four genes (PECAM1, VEGF R2, Ve-Cadherin and CXCR4) was expressed in a comparable way in both MSCs and S-MSCs. S-MSCs expressed a significant, 44-fold higher level of VCAM1 in comparison with MSCs. In contrast, S-MSCs expressed a significantly lower level of vWF (4.1-fold lower) in comparison with MSCs. In cb-ECFCs, the level of expression of vWF, PECAM1, VEGF R2, Ve-Cadherin and CXCR4 was significantly higher in comparison with MSCs and S-MSCs.

\section{Phenotype of isolated MSCs and S-MSCs}

The cultured MSCs express on their surface CD105+, CD90+ and CD73+, while lacking the expression 

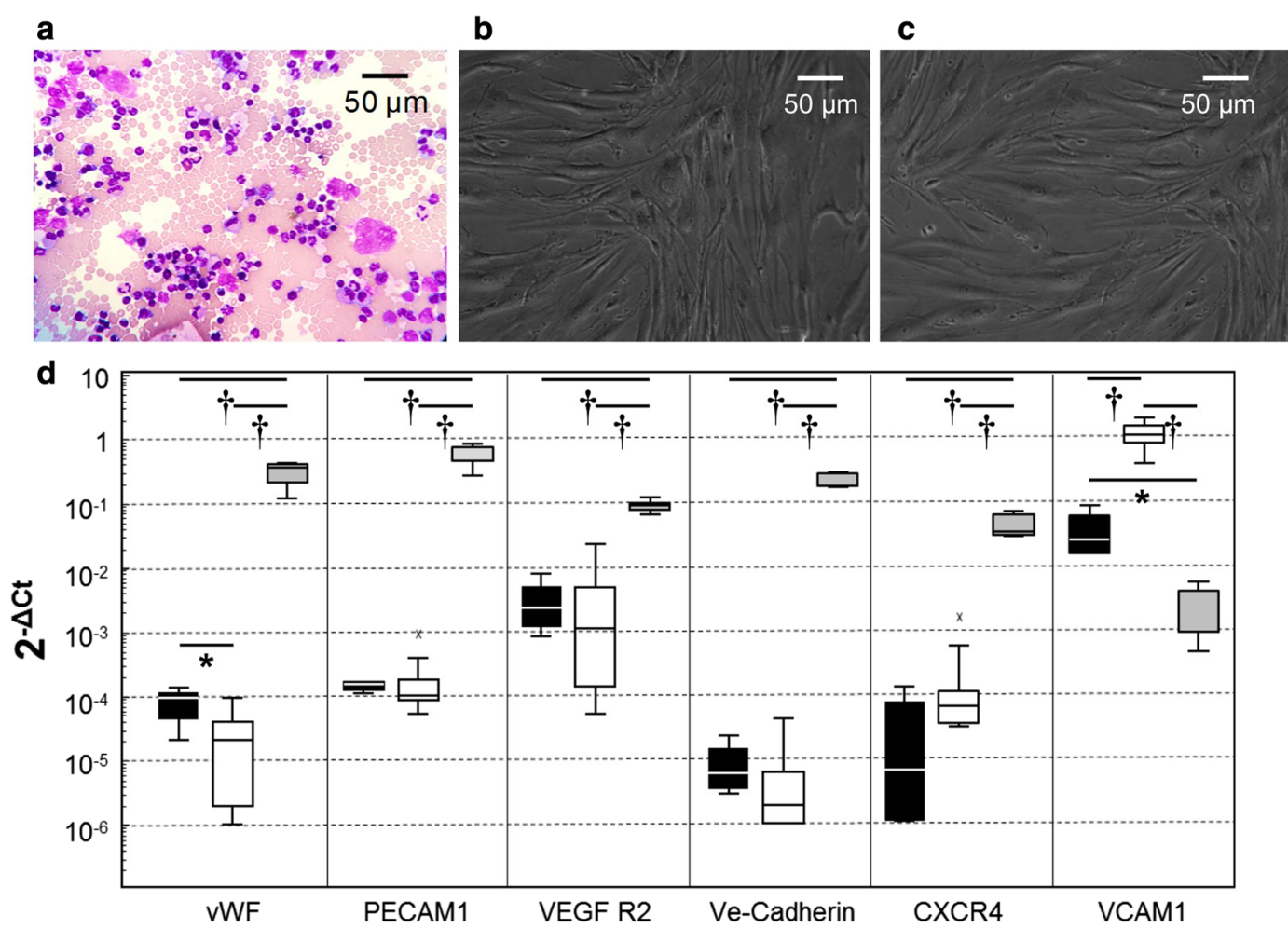

Fig. 2 Cells observation and real-time RT-PCR analysis. a BMCs morphology in May Grünwald Giemsa staining. b MSCs morphology in phase contrast microscopy. c S-MSCs morphology in phase contrast microscopy. $\mathbf{d}$ mRNA expression of six genes of interest were quantified using simultaneous real-time RT-qPCR experiments in MSCs (black box, $n=7$ ), in S-MSCs (empty box, $n=7$ ) and cb-ECFC (grey box, $n=5$ ) used as control. $\mathrm{x}$ : aberrant distribution values as indicated by Box and Whiskers plots Medcalc version 7.3 software $\left({ }^{*} p<0.05\right.$ and $\left.{ }^{\dagger} p<0.01\right)$

of hematopoietic cell markers (CD45-, CD34-, CD11b-) and HLA-DR surface marker (Fig. 3b). The MSCs were strongly positive for CD146 (MCAM), CD140b (PDGF RB), weakly positive for CD140a (PDGF RA) and negative for endothelial-specific markers (CD31, CD144, VEGF R1, VEGF R2), CD184 (CXCR4) and CD106 (VCAM1).

S-MSCs grown in EGM-2 during 2 weeks showed the classic pattern of MSCs (CD105+, CD90+, CD73+, CD45-, CD34-, CD11b- and HLA-DR-) but did not express endothelial-specific markers (CD31, CD144, VEGF R1, VEGF R2). S-MSCs retained the expression of CD90 and acquired the CD106 marker (VCAM1) (Fig. 3b). For both markers, a double population of cells (with 2 distinct mean fluorescence intensity) was observed in all S-MSCs obtained from 7 CLI-patients (data not shown).

Taken together, mRNA and protein levels of CD31, Ve-Cadherin, VEGF R2 and CXCR4 were not significantly increased in S-MSCs. On the contrary, VCAM1 was up-regulated in S-MSCs.

\section{Cell secretome}

Therapeutic potential of undifferentiated MSCs can be attributed to their capacity to secrete bioactive factors, which may potentially affect both local and systemic physiological processes. Thus, we investigated the effects of EGM-2 medium on the secretome of S-MSCs at day 28 in comparison with MSCs (Table 2). The levels of FGF2, EGF and IGF-1 measured in the S-MSCs culture supernates were significantly lower than in cell-free EGM-2 culture media. A similar pattern was observed in IGF-1 level in the MSCs culture supernates in comparison with cell-free CFU-F culture media. PDGF-AA, Angio-1, LIF-1, CXCL12, IL-6 and HGF are absent from CFU-F and EGM-2 media. Both S-MSCs and MSCs secreted HGF and VEGF-A at a comparable level. In opposite, S-MSCs secreted significantly higher PDGF-AA (22.9-fold higher), Angio-1 (5.6-fold higher), LIF-1 (3.1-fold higher) and lower IL-6 (11.8-fold lower) than MSCs. Interestingly, S-MSCs completely lost their ability to secrete CXCL12.

HMEC-1 suspended in endothelial cell growth medium MV were able to form pseudo-tubes in a Matrigel assay (Positive control) (Fig. 4a. HMEC-1 did 


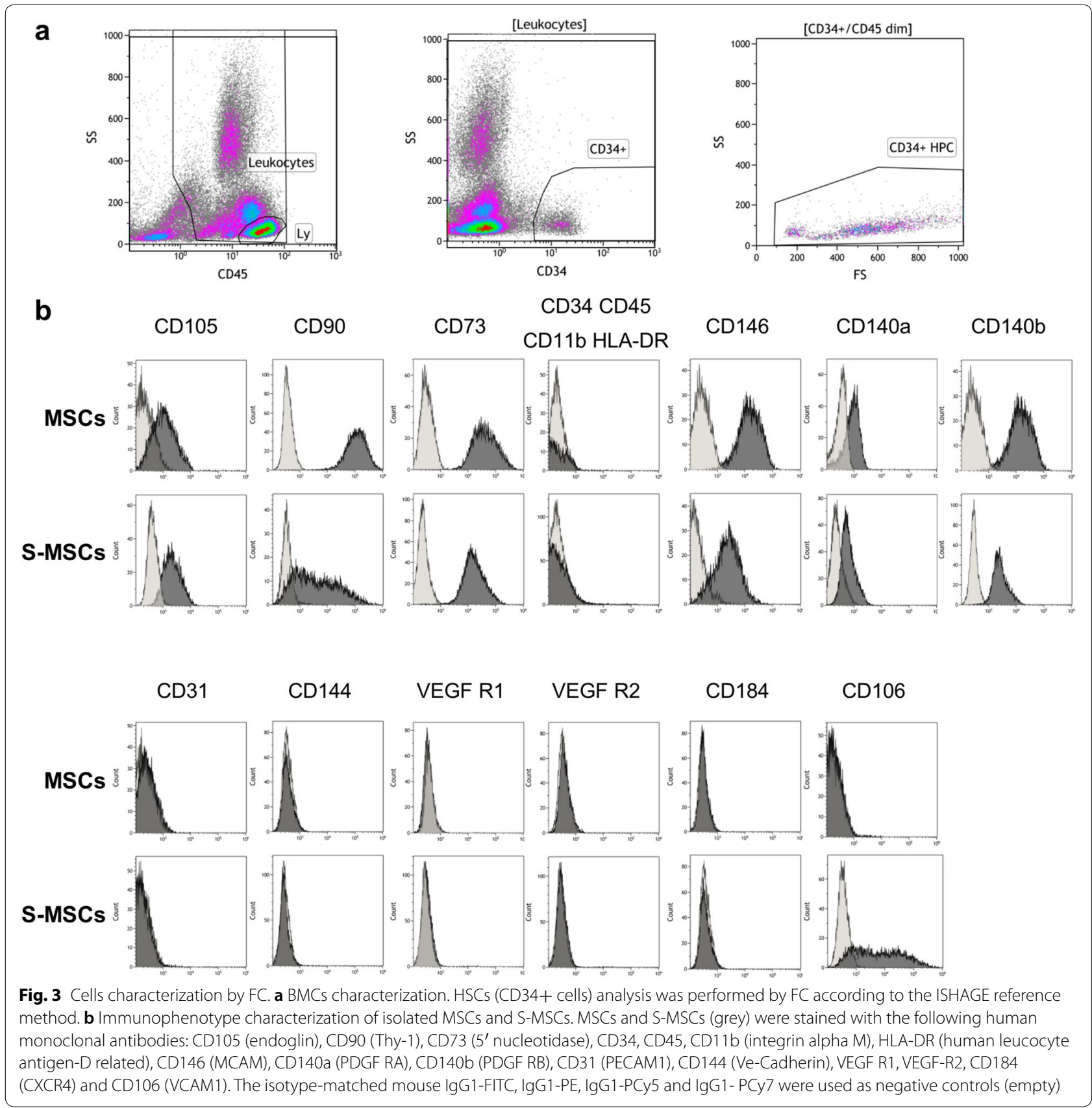

not form any pseudo-tubes when suspended in CFU-F medium. When suspended in MSCs culture supernates, HMEC-1 could form short tubes lacking branching points and loops. On the contrary, HMEC-1 could generate a network of pseudo-tubes when suspended in S-MSCs culture supernates. This network was significantly more developed when HMEC-1 were suspended in S-MSCs in comparison with MSCs culture supernates $(p<0.0002)$ but also with cell free EGM-2 medium $(\mathrm{p}<0.013)$.
Taken together, our results indicated that MSCs and S-MSCs can be distinguished by their secretome profiles in terms of growth factors productions and also in terms of functional capacity to form tube-like structures.

\section{Cell functional assay: in vitro tube formation assay}

Because MSCs and S-MSCs have a proangiogenic potential, we looked for their ability to form capillary-like tube in an in vitro endothelial tube formation assay. Contrary to MRC5 fibroblasts cells line used as negative control, 
Table 2 Secretome

\begin{tabular}{|c|c|c|c|c|c|}
\hline & \multicolumn{2}{|c|}{ CFU-F medium } & \multicolumn{2}{|l|}{ EGM-2 medium } & \multirow[t]{2}{*}{$p^{b}$} \\
\hline & $\begin{array}{l}\text { CFU-F } \\
\text { medium }\end{array}$ & MSCs culture supernates & EGM-2 medium $^{a}$ & S-MSCs culture supernates & \\
\hline VEGF-A (pg/mg proteins) & $\emptyset$ & $272[182-478]$ & 180 & $464[288-627]$ & $N S^{c}$ \\
\hline FGF2 (pg/mg proteins) & $\emptyset$ & $\emptyset$ & 101 & $7[4-16]$ & 0.003 \\
\hline EGF (pg/mg proteins) & $\emptyset$ & $\emptyset$ & 5056 & $1643[736-3710]$ & 0.003 \\
\hline IGF-1 (pg/mg proteins) & 332 & $154[35-308]$ & 826 & 319 [150-452] & $0.003^{c}$ \\
\hline PDGF-AA (pg/mg proteins) & $\emptyset$ & $0.9[n d-13]$ & $\varnothing$ & $20[3-60]$ & 0.003 \\
\hline Angio-1 (pg/mg proteins) & $\emptyset$ & $159[91-377]$ & $\emptyset$ & $899[371-2234]$ & 0.003 \\
\hline LIF (pg/mg proteins) & $\emptyset$ & $49[31-82]$ & $\emptyset$ & 149 [99-283] & 0.003 \\
\hline CXCL12 (pg/mg proteins) & $\emptyset$ & 3475 [1418-6987] & $\emptyset$ & $\emptyset$ & 0.003 \\
\hline IL-6 (pg/mg proteins) & $\emptyset$ & $741[479-1202]$ & $\emptyset$ & $63[4-127]$ & 0.003 \\
\hline HGF (pg/mg proteins) & $\emptyset$ & $17[1-44]$ & $\emptyset$ & 4 [nd-159] & NS \\
\hline \multicolumn{6}{|c|}{$\begin{array}{l}\text { A set of ten growth factors [VEGF-A, EGF, FGF2, IGF-1, Angio-1, IL-6, HGF, PDGF-AA, LIF, SDF-1 (or CXCL12)] was measured in the MSCs }(n=7) \text { and S-MSCs ( } n=7 \text { ) culture } \\
\text { supernates at day } 28 \text { and in CFU-F and EGM-2 media }\end{array}$} \\
\hline \multicolumn{6}{|c|}{ NS not significant, $\emptyset$ undetectable } \\
\hline \multicolumn{6}{|l|}{ a Cell-free media } \\
\hline \multicolumn{6}{|c|}{ b Comparison of MSCs culture supernates versus S-MSCs culture supernates } \\
\hline
\end{tabular}

cb-ECFC were constitutively able to form pseudo-tubes in a Matrigel assay. MSCs have low ability for pseudo-tube formation compared with S-MSCs (p value $=0.0008)$. There was no difference between cbECFC and S-MSCs (Additional file 1: Figure S1).

\section{MSCs and S-MSCs are effective to restore hindlimb blood flow}

As MSCs and S-MSCs may have a stronger angiogenic potential than BMCs, we compared these cells with vehicle in ischemic Nude mice (Fig. 5). The mouse model was validated by the fact that the targeted ischemic ratio was obtained and was identical in each group at baseline $(0.99 \pm 0.05)$ and after surgery $(0.31 \pm 0.04)$. Figure $5 \mathrm{~b}$ shows statistical differences between groups. Whatever the type of cells, their injection was more effective to restore leg perfusion as measured by PeriCam ${ }^{\circledR}$ than vehicle $(\mathrm{p}<0.0001)$. MSCs and S-MSCs transplantation (Fig. 5b) allowed significant improvement of flow in comparison with BMCs [p value (MSCs vs. BMCs) $<0.0033$; $\mathrm{p}$ value $(\mathrm{S}-\mathrm{MSCs}$ vs. BMCs $)<0.0001]$. However, complete flow recovery after BMCs transplantation was not achieved at day 28. In comparison, MSCs allowed to fully restore the flow at day 20. S-MSCs were more effective than BMCs and MSCs and allow achieving full recovery at day 14 . Figure $5 \mathrm{c}$ shows the heterogeneity in terms of hindlimb blood flow recovery when BMCs are transplanted. In contrast, the response to MSCs and S-MSCs was homogeneous regardless the CLI-patient origin.
These results indicate that MSCs and S-MSCs are more effective than BMCs (and vehicle) to restore hindlimb blood flow.

\section{S-MSCs improves limb survival in comparison with MSCs}

Animal limbs were regularly observed during 28 days post operatively to detect necrosis. Ten out of 20 untreated mice developed necrosis as early as day 3 after ligation (Fig. 6). In contrast, in the BMCs group, necrosis affected 7 out of 40 (17.5\%) mice. The efficacy of BMCs injection on limb survival was significant compared with vehicle $(\mathrm{p}<0.001)$. In the MSCs group, necrosis was observed in 4 out of 35 (11.4\%) mice. MSCs significantly improved limb salvage in comparison with vehicle $(\mathrm{p}<0.001)$ but did not significantly differ from BMCs. In contrast, no necrosis was observed after S-MSCs injection, the necrosis rate being significantly reduced in comparison with BMCs but also with MSCs $(\mathrm{p}<0.05)$.

Taken together, these results suggest that S-MSCs have the strongest angiogenic potential in comparison with BMCs but also MSCs.

\section{MSCs and S-MSCs injection improves clinical recovery}

Cell injection using the three types of cells significantly improved clinical recovery in comparison with control group (Fig. 7). In all groups, static and dynamic tests were well-correlated (Pearson's test: $\mathrm{r}=0.6, \mathrm{p}<0.0001$ ).

In order to appreciate recovery, we measured IDS of the ischemic and of the controlateral non-ischemic paw, allowing us to calculate an IDS ratio (equal to 1 to achieve 
a

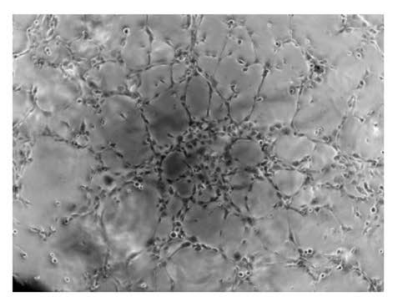

MV

medium

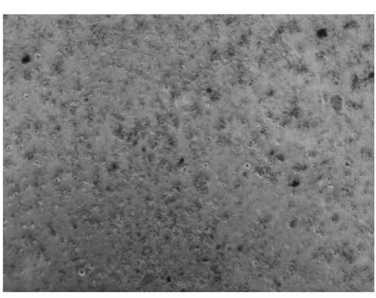

CFU-F

medium

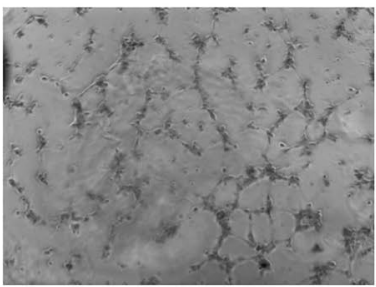

MSCs culture

supernates

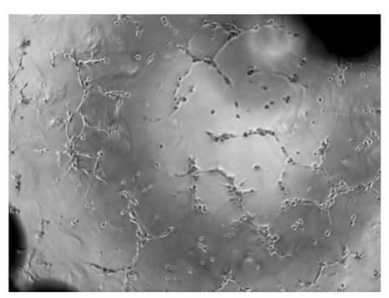

EGM-2

medium

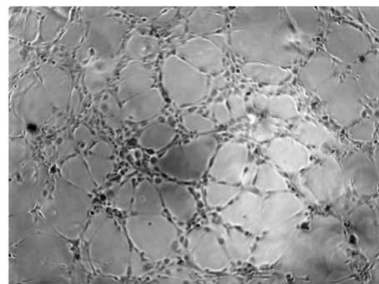

S-MSCs culture supernates

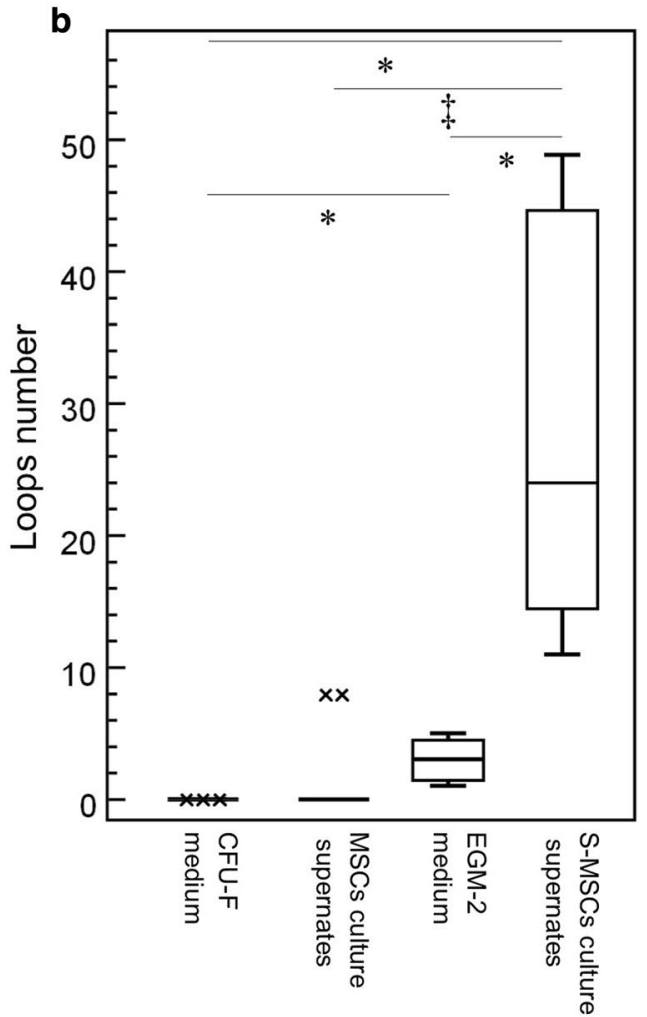

C

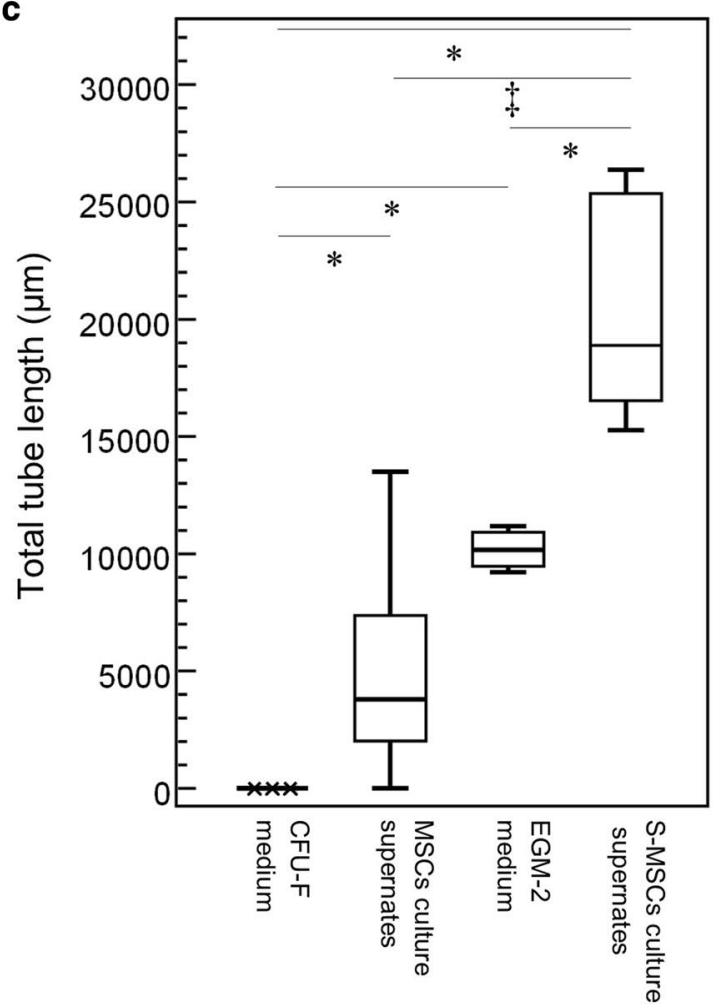

Fig. 4 Angiogenic effect of culture supernates. a MSCs and S-MSCs culture supernates and cell-free media (CFU-F and EGM-2) were recovered at day 28. HMEC-1 were suspended in endothelial cell growth medium MV $(n=3)$, in cell-free CFU-F medium $(n=3)$, in cell-free EGM-2 medium $(n=3)$, in MSCs culture supernates (obtained from 5 CLI-MSCs, $n=2$ each group), in S-MSCs culture supernates (obtained from 5 CLI-S-MSCs, $\mathrm{n}=2$ each group) and incubated on Matrigel during $24 \mathrm{~h}$. The extend of the network of the capillary-like tubes was appreciated at 3:30 h. $\mathbf{b}$ Quantification of the loops number at 3:30 h. c Quantification of total tube length $(\mu \mathrm{m})$ at 3:30 h. x: aberrant distribution values as indicated by Box and Whiskers plots Medcalc version 7.3 software $\left({ }^{*} p<0.05,{ }^{\dagger} p<0.01\right.$ and $\left.{ }^{\ddagger} p<0.001\right)$ 


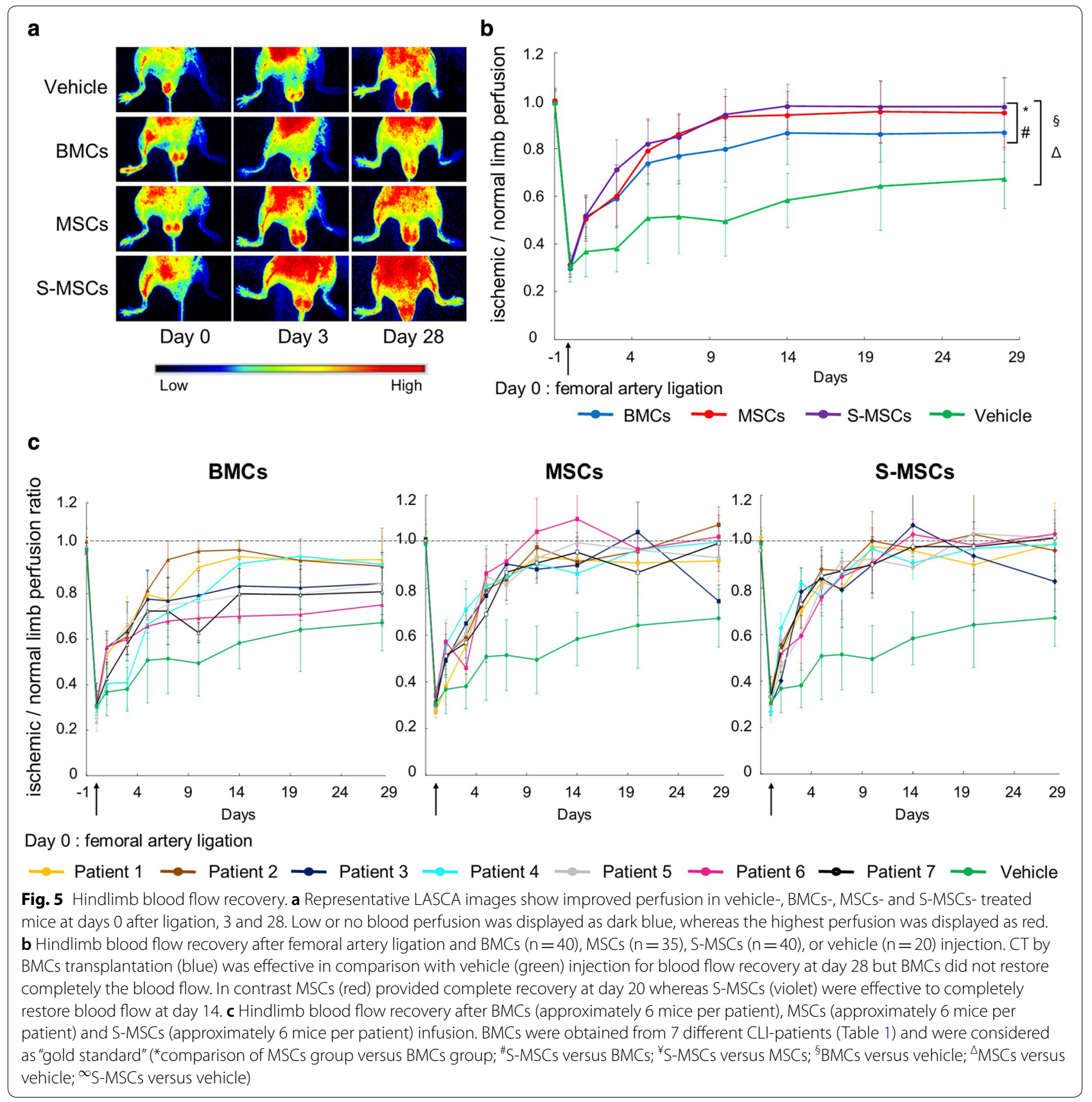

full recovery) (Fig. 7a). BMCs significantly improved IDS ratio evaluated at day 28 in comparison with vehicle (IDS ratio BMCs: $0.84 \pm 0.15$; vehicle: $0.67 \pm 0.20$, $\mathrm{p}<0.001)$. MSCs and S-MSCs were significantly more effective than BMCs on IDS ratios at day 28 [IDS ratio MSCs: $0.90 \pm 0.11$; S-MSCs: $0.93 \pm 0.09$; p (MSCs vs. BMCs) $<0.05$; p (S-MSCs vs. BMCs) $<0.001$; MSCs vs. $\mathrm{S}-\mathrm{MSCs}=$ non-significant) (Fig. 7b).

Cell injection of BMCs, MSCs or S-MSCs significantly improved the walking of the ischemic mice as assessed by the dynamic test $(\mathrm{p}<0.0001)$ (Fig. 7c). Indeed, in the absence of cell infusion, the walking score of the ischemic mice progressively improved barely achieving full recovery at day 28 . On the contrary, full recovery was obtained at day 20 after cell infusion, whatever the type of cells used.

\section{S-MSCs improve angiogenesis and arteriogenesis in ischemic muscle}

In order to visualize neoangiogenesis after cell infusion, capillary density in the semimembranosus (Fig. 8a) and 
a

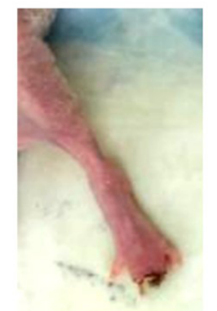

BMCs day 28

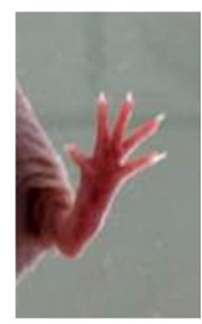

S-MSCs day 28 Vehicle day 28

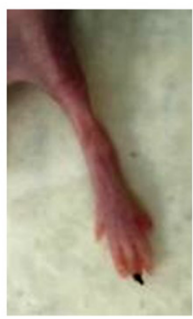

MSCs day 28 b
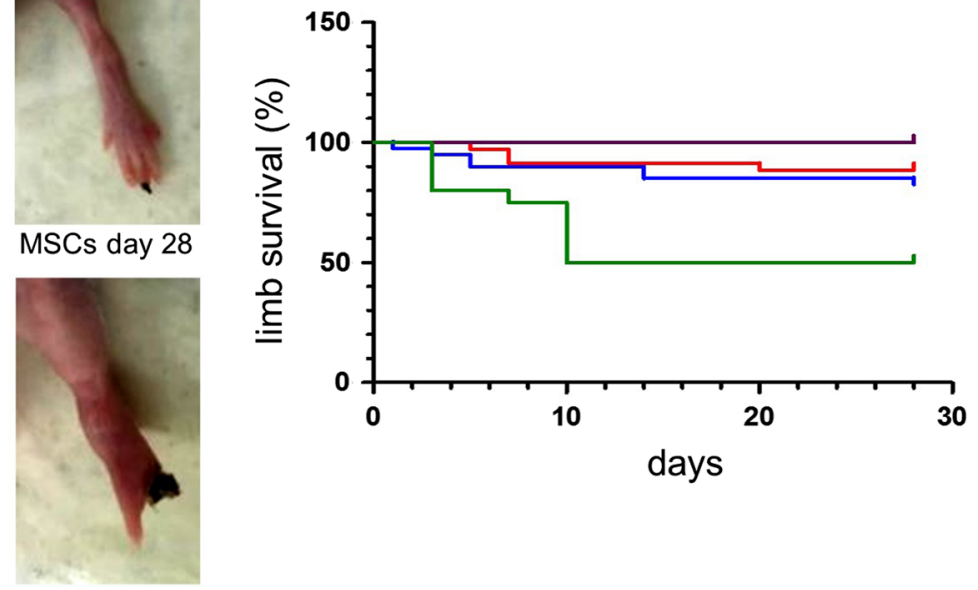

- BMCs

- MSCs

- S-MSCs

$\rightarrow$ Vehicle

Fig. 6 Limb survival. a S-MSCs provide complete limb salvage in comparison with MSCs and BMCs. b In comparison with vehicle ( $\mathrm{n}=20$ ), BMCs $(n=40)$ provided better limb salvage $(p<0.001)$. There was no difference between BMCs and MSCs $(n=35)$ treatment. S-MSCs $(n=40)$ were the most protective compared to BMCs and MSCs $(p<0.05)$

gastrocnemius (Fig. 8b) muscles was assessed by immunofluorescence after CD31 labelling. A ratio was calculated from the fluorescence intensity (CD31+) in the ischemic gastrocnemius muscle in comparison with the non-ischemic controlateral muscle (Fig. 8c). Capillary density was the highest after S-MSCs injection (S-MSCs fluorescence ratio: $6.31 \pm 0.96 ; \mathrm{p}<0.05$ vs. MSCs) (Fig. 8c).

In order to visualize arteriogenesis, we looked at the presence of smooth muscle vascular cells associated with vessels in the gastrocnemius and semimembranosus muscles (Fig. 8a, b). For this, doubly labelled arterioles $(\mathrm{CD} 31+/ \alpha \mathrm{SMA}+)$ were assessed. The analysis of the ischemic semimembranosus muscle revealed that the CD31 and $\alpha$ SMA-positive vessels had a larger lumen diameter than the arterioles observed in controlateral normal muscle (Fig. 8a) and that in gastrocnemius muscles (Fig. 8b). In gastrocnemius muscles, the infusion of either BMCs, MSCs or S-MSCs did not change the aspect of the vessels in comparison with vehicle (Fig. 8b). A ratio was calculated from the fluorescence intensity $(\mathrm{CD} 31+/ \alpha \mathrm{SMA}+)$ in the ischemic gastrocnemius muscle in comparison with the non-ischemic controlateral muscle (Fig. 8d). The injection of BMCs did not increase the number of CD31 and $\alpha$ SMA-positive vessels in comparison with vehicle (Fig. 8d). In contrast, MSCs treated mice developed a higher rate of CD31 and $\alpha$ SMApositive cells in comparison with BMCs $(1.92 \pm 0.36$ vs. $1.46 \pm 0.53, \mathrm{p}<0.05)$. Interestingly, $\mathrm{S}-\mathrm{MSCs}$ treated mice presented with the highest CD31 and $\alpha$ SMA-positive pattern (S-MSCs fluorescence ratio: $2.38 \pm 0.54 ; \mathrm{p}<0.05$ vs. MSCs). These results suggest that MSCs and S-MSCs can induce CD31 and $\alpha$ SMA-positive vessels whereas BMCs cannot.

As inflammation is a strong modulator of angiogenesis, we evaluated the macrophage infiltration in response to cell infusion using a CD68 labeling. We found no difference in CD68-positive cell counts after the injection of either type of cells BMCs, MSCs and S-MSCs. Still, there was a difference between either cell type in comparison with vehicle (fluorescence ratio BMCs: $8.72 \pm 3.06$; MSCs: 9.26 \pm 3.37 ; S-MSCs: $9.71 \pm 3.54$; vehicle: $12.1 \pm 2.18$, p value for each type of cells vs. vehicle: $\mathrm{p}<0.05)$.

\section{S-MSCs favor muscle repair after ischemia}

A histological analysis of semimembranosus (Fig. 9a) and gastrocnemius (Fig. 9b) muscles was performed to visualize ischemic muscle damage and muscle repair after cell infusion. For this, the percentage of muscle fibers with a central nucleus was determined. Ligation provoked ischemic lesions which were still visible at day 28 in both muscles. In the ischemic semimembranosus, the muscle damage was comparable whatever the type of infused cells (Fig. 9a). In contrast, in the ischemic gastrocnemius, there was a glaring difference depending on the type of infused cells (Fig. 9b). BMCs failed to favor gastrocnemius repair ( $37 \pm 18 \%$ expressed as a percentage of total muscle fibers), in comparison with vehicle $(33 \pm 20 \%)$ (Fig. 9c). 


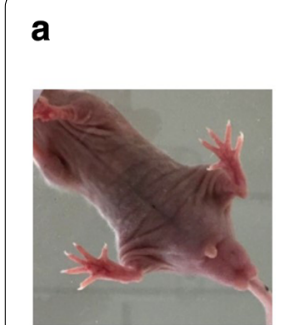

Baseline

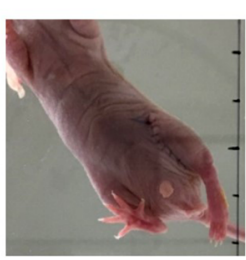

Post ligation

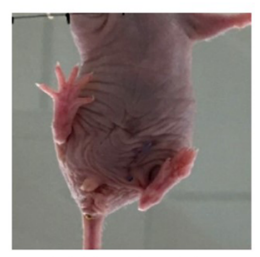

BMCs day 28

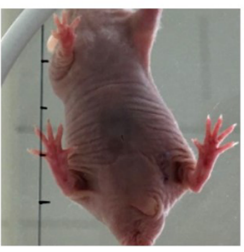

S-MSCs day 28

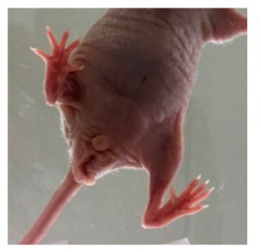

MSCs day 28

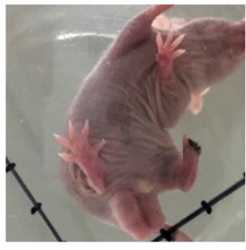

Vehicle day 28
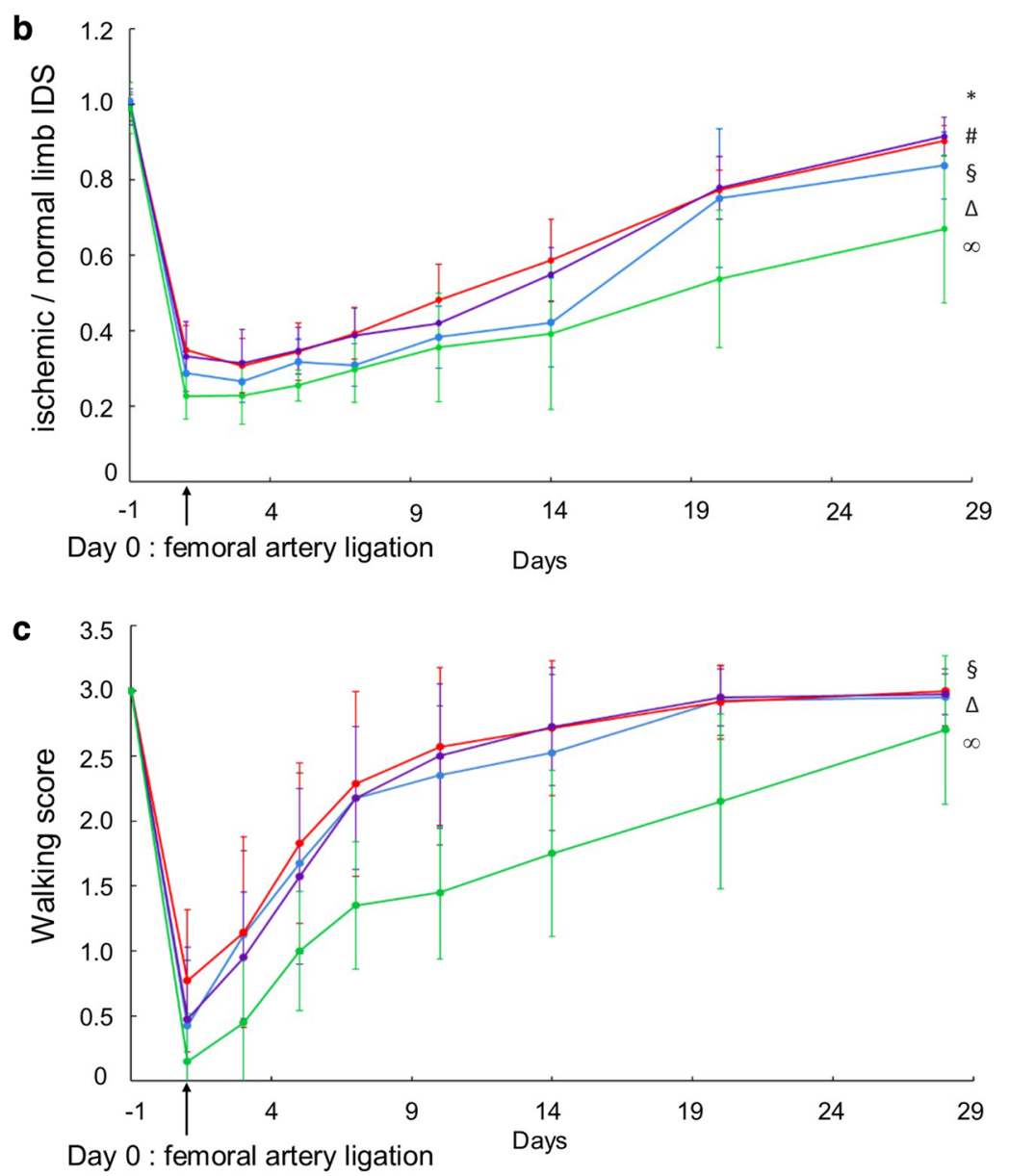

Day 0 : femoral artery ligation

Fig. 7 Functional tests (static and dynamic). a, b Static tests: MSCs and S-MSCs were significantly more effective than BMCs and vehicle to improve IDS. MSCs (red) and S-MSCs (violet) provided significantly higher ratios at day 28 in comparison with BMCs (blue). There was no difference between the MSCs and S-MSCs groups. c Dynamic test: S-MSCs, MSCs and BMCs were effective to restore a normal walk in comparison with vehicle $\left[{ }^{*}\right.$ comparison of MSCs group $(n=35)$ versus BMCs group $(n=40) ;$ \#S-MSCs $(n=40)$ versus BMCs; ${ }^{*}$ S-MSCs versus MSCs; ${ }^{\S}$ BMCs versus vehicle $(n=20) ;{ }^{\triangle}$ MSCs versus vehicle; ${ }^{\infty}$ S-MSCs versus vehicle]

MSCs did increase the rate of myofibers with central nuclei $(46 \pm 15 \%)$, in comparison with vehicle $(\mathrm{p}<0.01)$. The effect of S-MSCs on muscle repair $(74 \pm 20 \%)$ was significantly stronger than vehicle $(\mathrm{p}<0.001)$ and BMCs $(\mathrm{p}<0.001)$. Interestingly, S-MSCs were more effective than MSCs on ischemic muscle repair $(\mathrm{p}<0.01)$. This indicates that S-MSCs may favor gastrocnemius repair more efficiently than MSCs after ischemia.

\section{Absence on human nucleus at the end of the experiment} At day 28, a real time qPCR was performed on DNA extracted from gastrocnemius muscles in order to detect human nucleus. Human DNA was used as positive control (Ct of human Factor V gene $=24.1 \pm 0.1$ ). Gastrocnemius muscles of vehicle group and non-ischemic controlateral muscles did not contain any detectable human DNA (Ct of human Factor $\mathrm{V}$ gene $>35$ ). No human DNA ( $\mathrm{Ct}$ of human Factor V gene $>35$ ) was found in ischemic and injected gastrocnemius muscles, whatever the type of cells (BMCs, MSCs or S-MSCs). This suggests the absence of any residual human cell at the end of the experiment.

\section{Discussion}

Among innovative therapies, $\mathrm{CT}$ is a good candidate to treat patients with severe PAD. BMCs are considered as "gold standard" in CLI-CT because it was used by the founder trial [4]. In spite of encouraging clinical studies, the efficacy of CT remains controversial $[7,8]$. This may be partially explained by the heterogeneity of autologous 


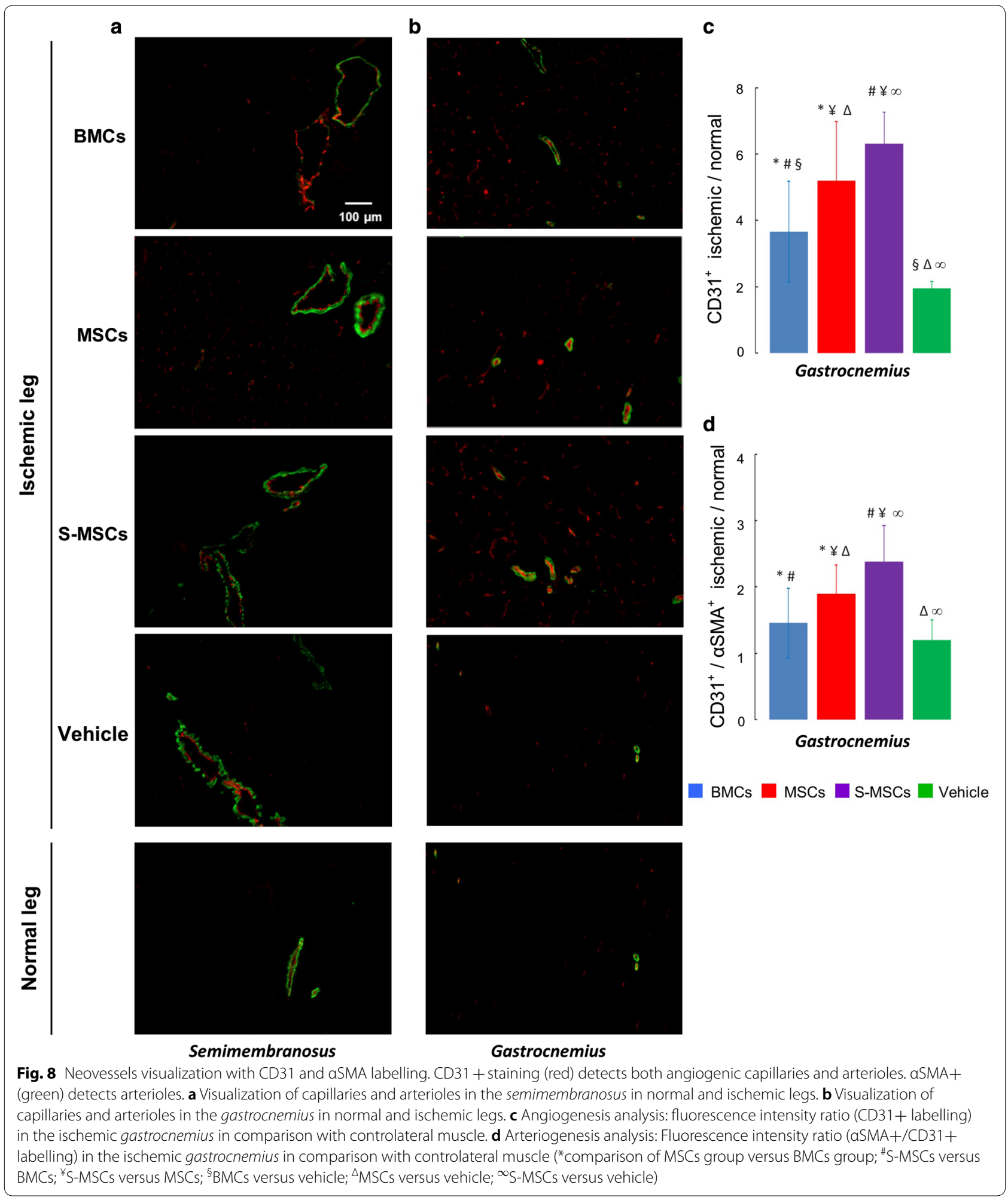

BMCs [11]. In such BMCs, HSCs are extremely rare and may not support proangiogenic properties of BMCs [5]. Still, these autologous BMCs may be the source of other types of proangiogenic stem cells. Indeed undifferentiated MSCs were obtained from BMCs CLI-patients as previously described $[11,29,36]$. 


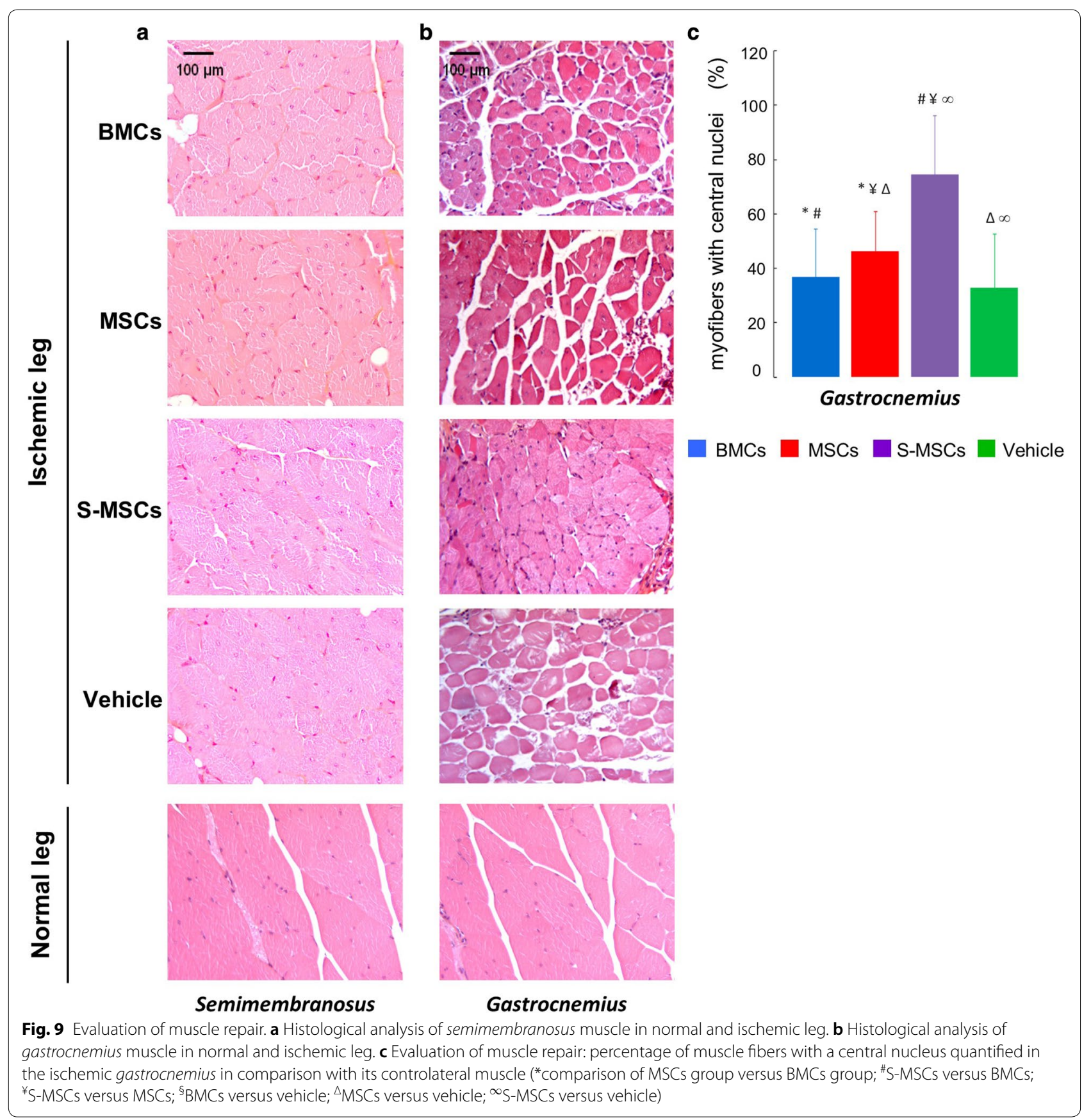

MSCs are well-recognized for their high proliferation and differentiation potential. MSCs support a significant paracrine effect through the secretion of proangiogenic cytokines which provide anti-apoptotic effects and stimulate revascularization [15].

In the first step of our study, we confirmed the presence of MSCs in CLI-BMCs. We next evaluated if the culture of MSCs in a medium enriched in endothelial growth factors (EGM-2) could improve the proangiogenic properties of MSCs that we named S-MSCs. S-MSCs that we obtained from CLI-patients showed a morphology which was indistinguishable from MSCs obtained in CFU-F medium. However, S-MSCs' doubling time was shorter for when compared with MSCs', in agreement with published data [21, 25, 37].

We next characterized S-MSCs in FC and observed that these cells did not express endothelial markers (CD31, Ve-Cadherin, VEGF R1 and VEGF R2). Using 
other sources of MSCs derived from umbilical cord blood [25, 26], adipose tissue [22, 23, 27] or BM, but from healthy donors [21], an endothelial differentiation of MSCs was reported when cultured in EGM-2 medium [37]. Oswald et al. was the first to report that a VEGF induction gave rise to the endothelial differentiation of MSCs expression classical endothelial markers but not CD31 [38]. Tancharoen et al. also, showed that S-MSCs expressed endothelial markers including CD31 but with a much lower level than HUVECs [39]. In agreement with our data, other published studies on WJ-MSCs [32], BM-MSCs [40] or diabetic patients ADSCs [41], stated that endothelial cell growth supplement alone could not per se induce the expression of molecular markers of ECs. This illustrates the difficulty encountered to define such cells when cultured in different conditions. The term of "endothelial-like cells" has been employed by some authors [21, 32, 40, 42] in spite of a high heterogeneity in both culture conditions and MSCs origin. Interestingly, it was suggested that shear stress could be a major parameter for endothelial differentiation [40].

Our data show that MSCs and S-MSCs express comparable proteomic and transcriptomic profiles except for VCAM1 which is significantly higher in S-MSCs. VCAM1 mediated the interaction of MSCs with ECs, which is essential for MSCs homing [43]. This expression of VCAM1 was previously reported in S-MSCs obtained in the presence of VEGF-A [38]. A role of EGF, which is present in EGM-2 medium, has been shown to increase VCAM1 and MSCs adhesion to ECs [44].

To further characterize S-MSCs, we analyzed their secretion capacity. For this, we quantified a set of ten growth factors in S-MSCs culture supernates in comparison with MSCs. Our data indicate major differences between these two types of cells: in comparison with MSCs, S-MSCs produce high levels of PDGF-AA, Angio-1 and LIF whereas the secretion of pro-inflammatory IL-6 is significantly lower. CXCL12 is not secreted by S-MSCs whereas it is found at high concentration in the MSCs supernatant. The loss of capacity of S-MSCs to secrete CXCL12 could be the consequence of EGM-2 induction. Using a supplementation with platelet-rich plasma, which contains PDGF, TGF $\beta 1$, FGF2, IGF-1, VEGF and EGF (some of them being also present in EGM-2 medium), Goedecke et al, have reported a loss of CXCL12 secretion associated with a defect in HSCs migration [45]. The analysis of S-MSCs supernatants indicated the diminution in the concentration of FGF2, EGF and IGF-1 present in the EGM-2 medium. This may be the consequence of a consumption or could be explained by the endocytosis of a ligand-receptor complex.
In order to further characterize the secretome, we evaluated the capacity of supernates to induce tube-like structures from HMEC-1. We observed that S-MSCs culture supernates had the strongest ability to induce tube-like structures. This is in agreement with the results of growth factor quantification showing that S-MSCs supernates contain higher concentrations of proangiogenic factors. Taken together, these results suggest that the secretome analysis allows to differentiate S-MSCs from MSCs. A further issue would be to elucidate the potency of each growth factor present in conditioning media. Furthermore, the existence of possible autocrine mechanisms has to be considered.

Our study shows that S-MSCs can be functionally distinguished from MSCs by their stronger capacity to form pseudo-tubes in vitro. This confirms most reports having used EGM-2 induction [21-23, 25, 40, 41, 46]. However, Choi et al, raised the point that MSCs are able to form tube-like structures in Matrigel but the observation of these pseudo-tubes by electron microscopy revealed the absence of lumen [32]. Although commonly used, Matrigel cannot be considered as a specific angiogenic assay [47].

It was therefore mandatory to evaluate in vivo, the proangiogenic potential of MSCs and S-MSCs. In a well-established mouse model of HLIM [30], our results clearly indicate that MSCs from CLI-patients completely restore blood flow (primary endpoint) in comparison with BMCs that we considered as the "gold standard". Such results are in agreement with those obtained by Iwase et al, who concluded that BM-MSCs were superior to BMCs in promoting neovascularization [48]. The limit of this study was that BM-MSCs were obtained from young rats. Indeed, it has been shown that age could impair stem cell properties [9]. In the context of CLI, this alteration could be further increased in case of associated risk factors [20]. In contrast, MSCs obtained from CLI-patients conserve proangiogenic properties through a paracrine mechanism $[15,29,49]$. This may be at least partly explained by the fact that, BM-MSCs from CLIpatient have a similar secretome profile compared to that of healthy MSCs $[29,50]$. In agreement with this hypothesis, Smadja et al, 2012 and Gremmels et al, 2014 showed, in a HLIM model, that MSCs from CLI-patients had a comparable proangiogenic potential to MSCs isolated from age matched patients free of any cardiovascular disease $[29,36]$.

To our knowledge, this is the first report to establish the property of S-MSCs obtained from CLI-patients infused in HLIM model. Interestingly, S-MSCs restored completely blood flow and earlier than MSCs. The infusion of BMCs led to a highly heterogeneous response in terms of extend and kinetics of blood flow recovery. This fits with 
the heterogeneity of BMCs in terms of cellular content. In contrast, the infusion of MSCs and S-MSCs restored blood flow in a homogeneous manner. The selection and amplification in culture may allow to obtain a consistent favorable response to infusion, and this whatever the patient's clinical status.

We further demonstrated that MSCs and S-MSCs could improve clinical recovery as well as limb salvage. In agreement with Iwase et al, MSCs were more effective than BMCs to save limb [48]. Our results indicate that S-MSCs were also more effective than MSCs.

Interestingly, the analysis of the gastrocnemius muscle clearly shows that S-MSCs not only enhance neovascularization but also favor the development of vascular muscle cells suggesting the formation of mature and stable capillaries [51]. Indeed, arteriogenesis is more capable of restoring tissue blood supply than angiogenesis [52]. Collateral vessels have the capacity to carry a larger volume of blood than sprouting capillary networks [53].

In contrast, the analysis of the semimembranosus muscle indicates an enlargement of the vessels and limited ischemia. This is explained by the anatomic situation of this muscle which is located proximally to the ligation site. It was reported that, following a femoral artery ligation, an arteriogenic process is initiated by the increase of blood pressure in the pre-existing collaterals that circumvent the obstruction and can supply blood flow to the distal tissue [54]. In contrast, gastrocnemius muscle being downstream from the ligation site is more sensitive to ischemia and therefore prone to undergo a process of angiogenesis. In this respect, our results clearly show the favorable effect of cell infusion. This effect may be more the consequence of a paracrine effect considering the high potential of secretion of such cells. The proangiogenic effect is unlikely related to endothelial differentiation of infused cells since no human DNA was detected at the end of the experiment. Previous studies have illustrated the rapid disappearance of infused cells $[55,56]$.

A major advantage of S-MSCs may be their capacity to improve skeletal muscle repair after ischemia. This effect could explain the efficacy of S-MSCs to reduce the amputation rate. To evaluate muscle repair, we quantified myofibers with central nucleus location. Indeed, muscle regeneration is characterized by the activation of myogenic cells which leads to the formation of new myofibers. These fibers are recognized by a centrally located myonucleus [34, 35, 57, 58].

MSCs have been evaluated in 13 clinical trials in the last decade $[17-19,59-66]$ and have included a total population of 216 MSCs-treated patients. These studies have established the safety of such cells $[18,67]$, which may be at least partly explained by their immunomodulatory properties $[16,68,69]$. Clinical trial results were in favor of efficacy, one randomized clinical trial concluding that MSCs were more effective than BMCs [17].

Our study pointed out the importance of the secretome. This should be extended to the analysis of secretome content including extracellular vesicles, exosomes, microRNAs, mRNAs, long non-coding RNAs, circular RNAs which may have an interest in CLI-therapeutics $[15,70]$.

\section{Conclusions}

MSCs have been suggested to be a promising alternative source for ischemic diseases [42].

The present study shows that S-MSCs can be obtained from the BM of patients presenting severe PAD. S-MSCs can restore blood flow as efficiently as MSCs and more potently than BMCs. A major issue of CT in PAD is to provide a fully stable and mature vascular network. In this regard, S-MSCs are promising candidates as they restore flow in CLI and provide muscle repair. Many suggested improvements can be proposed to produce these cells for CLI-cell therapy. MSC secretome may also be of therapeutic value.

\section{Additional file}

\begin{abstract}
Additional file 1: Figure S1. Cell functional assay: in vitro tube formation assay. a MRC5 $(n=5)$, cb-ECFC $(n=4), \operatorname{MSCs}(n=7)$ and S-MSCs $(n=7)$ were incubated on Matrigel. The extend of the network of the capillarylike tubes was appreciated at the time of maximal network. b S-MSCs form more cord-like structures than MSCs (cb-ECFC are used as positive control and MRC5 as negative control). The extend of the network of the capillary-like tubes was appreciated at the time of maximal network by the quantification of the loops number. $\left({ }^{\dagger} p<0.01\right.$ and $\left.{ }^{\ddagger} p<0.001\right)$.
\end{abstract}

\section{Abbreviations}

ADSCs: adipose tissue-derived stem cells; Angio-1: angiopoietin-1; BALI: bone marrow autograft in limb ischemia; BM: bone marrow; BMCs: bone marrow derived cells; cb-ECFCs: cord blood endothelial colony-forming cells; CDH5: Ve-Cadherin (CD144); CFU-F: colony forming unit-fibroblast; CLI: critical limb ischemia; CT: cell therapy; CXCL12: chemokine CXC motif ligand 12 (or stromal-cell-derived factor-1; SDF-1); CXCR4: CXC motif receptor 4 (CD184); ECs: endothelial cells; EGM-2: endothelial basal medium-2; EGF: epidermal growth factor; FC: flow cytometry; FITC: fluorescein; FGF2: fibroblast growth factor-2 (basic FGF); HE: hematoxylin-eosin; HGF: hepatocyte growth factor; HLA-DR: human leukocyte antigen-D related; HLIM: hind limb ischemia model; HMEC-1: human microvascular endothelium cells; HSCs: hematopoietic stem cells; IDS: interdigital spacing; IGF-1: insulin-like growth factor-1; IL-6: interleukin-6; S-MSCs: stimulated-mesenchymal stem cells; LASCA: laser speckle contrast analysis; LIF: leukemia-inhibitory factor; MCAM: melanoma adhesion molecule (CD146); MNCs: mononuclear cells; MSCs: mesenchymal stem cells; NO-CLI:"no-option CLI"; PAD: peripheral arterial disease; PBS: phosphate buffer saline; PCR: polymerase chain reaction; PDGF-AA: platelet-derived growth factor, alpha polypeptide; PDGF RA: platelet-derived growth factor receptor alpha (CD140a); PDGF RB: platelet-derived growth factor receptor beta (CD140b); PE: phycoerythrin; PECAM1: platelet endothelial cell adhesion molecule-1 (CD31); PLTs: platelets; RT-qPCR: reverse transcriptase-quantitative real-time polymerase chain reaction; aSMA: alpha-smooth muscle actin; $\mathrm{TCPO}_{2}$ : transcutaneous partial pressure of oxygen; VCAM1: vascular cell adhesion molecule 1 (CD106); VEGF: vascular endothelial growth factor; VEGF R: vascular endothelial growth factor receptor; VWF: von Willebrand factor; WJ-MSCs: umbilical cord Wharton's jelly-derived mesenchymal stem cells; HLIM: hind limb ischemia model. 


\section{Acknowledgements}

The authors appreciated the contribution of Bernard Pignon, Blandine Dizier, Sandra Audonnet (Plateau technique de Cytometrie en flux URCACyt), Hélène Peyret, Damien Jolly, Zoubir Djerada, Catherine Macé, Catherine Deroche, Caroline Fichel, Aurore Bruhier, Lucie Rigolot and Victor Fournier.

\section{Authors' contributions}

CTournois and PN conceived the project. RA-R, NB, GP, CB-V, CTerryn and CF performed the experiments. MAS selected the eligible patients and created the clinical trial. CTournois, RA-R, PN, LK, contributed to the acquisition, analysis and interpretation of the data. CTournois, RA-R, and PN wrote the paper. All authors read and approved the final manuscript.

\section{Funding}

This study was supported by the European Science Research funding "FEDER" (Fonds européen de développement régional) and the Champagne Ardenne region.

\section{Availability of data and materials}

The data supporting the conclusions of this article are included within the article.

\section{Ethics approval and consent to participate}

The Bone Marrow Autograft in Limb Ischemia (BALI) protocol was approved by the French National Agency for Medicines and Health Products Safety and by an Institutional Review Board. The trial was registered on www.clinicaltrials. gov (identifier NCT00904501). Registered May 19, 2009, Study ID Numbers: PHRC2007-N11-02. Animal protocols were approved by the C2EA-56 (ethics committee in animal experimentation of Reims Champagne Ardenne, authorization number 4289-2016022217565171_v2).

\section{Consent for publication}

Patients were eligible for the BALI trial if they were $\geq 18$ years of age. All patients admitted to the hospital where the study was carried out sign a written informed consent for use of their data for research purposes, as approved by the institutional Ethics Committee.

\section{Competing interests}

The authors declare that they have no competing interests.

\section{Author details}

1 EA-3801, SFR CAP-santé, Université de Reims Champagne-Ardenne, 51092 Reims Cedex, France. ${ }^{2}$ Laboratoire d'Hématologie, CHU Robert Debré Reims, France. ${ }^{3}$ Laboratoire d'Anatomie Pathologique, Université de Reims Champagne-Ardenne, Reims, France. ${ }^{4}$ Plateforme PICT, Université de Reims Champagne Ardenne, Reims, France. ${ }^{5}$ Unité d'aide méthodologique CHU Robert Debré, Reims, France. ${ }^{6}$ Inserm UMR S1140, Faculté de Pharmacie de Paris, Paris, France. ${ }^{7}$ Université Paris Descartes, Sorbonne Paris Cité, Paris, France. ${ }^{8}$ Service de Médecine Vasculaire, CHU, Amiens, France.

Received: 18 November 2018 Accepted: 27 July 2019 Published online: 09 August 2019

\section{References}

1. Criqui MH, Aboyans V. Epidemiology of peripheral artery disease. Circ Res. 2015;116:1509-26.

2. Norgren L, Hiatt WR, Dormandy JA, Nehler MR, Harris KA, Fowkes FG. Inter-society consensus for the management of peripheral arterial disease (TASC II). J Vasc Surg. 2007;45(Suppl S):S5-67.

3. Gupta NK, Armstrong EJ, Parikh SA. The current state of stem cell therapy for peripheral artery disease. Curr Cardiol Rep. 2014;16:447.

4. Tateishi-Yuyama E, Matsubara H, Murohara T, Ikeda U, Shintani S, Masaki H, Amano K, Kishimoto Y, Yoshimoto K, Akashi H, et al. Therapeutic angiogenesis for patients with limb ischaemia by autologous transplantation of bone-marrow cells: a pilot study and a randomised controlled trial. Lancet. 2002:360:427-35.

5. Ai M, Yan CF, Xia FC, Zhou SL, He J, Li CP. Safety and efficacy of cellbased therapy on critical limb ischemia: a meta-analysis. Cytotherapy. 2016;18:712-24
6. Rigato M, Monami M, Fadini GP. Autologous cell therapy for peripheral arterial disease: systematic review and meta-analysis of randomized, nonrandomized, and noncontrolled studies. Circ Res. 2017;120:1326-40.

7. Peeters Weem SM, Teraa M, de Borst GJ, Verhaar MC, Moll FL. Bone marrow derived cell therapy in critical limb ischemia: a meta-analysis of randomized placebo controlled trials. Eur J Vasc Endovasc Surg. 2015:50:775-83.

8. Liew A, Bhattacharya V, Shaw J, Stansby G. Cell therapy for critical limb ischemia: a meta-analysis of randomized controlled trials. Angiology. 2016;67:444-55.

9. Dimmeler S, Leri A. Aging and disease as modifiers of efficacy of cell therapy. Circ Res. 2008;102:1319-30.

10. Pignon B, Sevestre MA, Kanagaratnam L, Pernod G, Stephan D, Emmerich J, Clement C, Sarlon G, Boulon C, Tournois C, Nguyen P. Autologous bone marrow mononuclear cell implantation and its impact on the outcome of patients with critical limb ischemia-results of a randomized, doubleblind, placebo-controlled trial. Circ J. 2017;81:1713-20.

11. Tournois C, Pignon B, Sevestre MA, Al-Rifai R, Creuza V, Poitevin G, Francois C, Nguyen P. Cell therapy in critical limb ischemia: a comprehensive analysis of two cell therapy products. Cytotherapy. 2017:19:299-310.

12. Friedenstein AJ, Gorskaja JF, Kulagina NN. Fibroblast precursors in normal and irradiated mouse hematopoietic organs. Exp Hematol. 1976:4:267-74

13. Mushahary D, Spittler A, Kasper C, Weber V, Charwat V. Isolation, cultivation, and characterization of human mesenchymal stem cells. Cytom A. 2018;93:19-31.

14. Chamberlain G, Fox J, Ashton B, Middleton J. Concise review: mesenchymal stem cells: their phenotype, differentiation capacity, immunological features, and potential for homing. Stem Cells. 2007;25:2739-49.

15. Vizoso FJ, Eiro N, Cid S, Schneider J, Perez-Fernandez R. Mesenchymal stem cell secretome: toward cell-free therapeutic strategies in regenerative medicine. Int J Mol Sci. 2017;18:1852-76.

16. Yong KW, Choi JR, Mohammadi M, Mitha AP, Sanati-Nezhad A, Sen A. Mesenchymal stem cell therapy for ischemic tissues. Stem Cells Int. 2018;2018:8179075.

17. Lu D, Chen B, Liang Z, Deng W, Jiang Y, Li S, Xu J, Wu Q, Zhang Z, Xie B, Chen S. Comparison of bone marrow mesenchymal stem cells with bone marrow-derived mononuclear cells for treatment of diabetic critical limb ischemia and foot ulcer: a double-blind, randomized, controlled trial. Diabetes Res Clin Pract. 2011:92:26-36

18. Gupta PK, Chullikana A, Parakh R, Desai S, Das A, Gottipamula S, Krishnamurthy S, Anthony N, Pherwani A, Majumdar AS. A double blind randomized placebo controlled phase I/II study assessing the safety and efficacy of allogeneic bone marrow derived mesenchymal stem cell in critical limb ischemia. J Transl Med. 2013;11:143.

19. Bura A, Planat-Benard V, Bourin P, Silvestre JS, Gross F, Grolleau JL, SaintLebese B, Peyrafitte JA, Fleury S, Gadelorge M, et al. Phase I trial: the use of autologous cultured adipose-derived stroma/stem cells to treat patients with non-revascularizable critical limb ischemia. Cytotherapy. 2014;16:245-57.

20. Barreto-Duran E, Mejia-Cruz CC, Leal-Garcia E, Perez-Nunez R, RodriguezPardo VM. Impact of donor characteristics on the quality of bone marrow as a source of mesenchymal stromal cells. Am J Stem Cells. 2018;7:114-20

21. Liu JW, Dunoyer-Geindre S, Serre-Beinier V, Mai G, Lambert JF, Fish RJ, Pernod G, Buehler L, Bounameaux H, Kruithof EK. Characterization of endothelial-like cells derived from human mesenchymal stem cells. J Thromb Haemost. 2007:5:826-34.

22. Ning $H$, Liu G, Lin G, Yang R, Lue TF, Lin CS. Fibroblast growth factor 2 promotes endothelial differentiation of adipose tissue-derived stem cells. J Sex Med. 2009;6:967-79.

23. Konno M, Hamazaki TS, Fukuda S, Tokuhara M, Uchiyama H, Okazawa $\mathrm{H}$, Okochi $\mathrm{H}$, Asashima M. Efficiently differentiating vascular endothelial cells from adipose tissue-derived mesenchymal stem cells in serum-free culture. Biochem Biophys Res Commun. 2010;400:461-5.

24. Bayes-Genis A, Soler-Botija C, Farre J, Sepulveda P, Raya A, Roura S, PratVidal C, Galvez-Monton C, Montero JA, Buscher D, Izpisua Belmonte JC. Human progenitor cells derived from cardiac adipose tissue ameliorate myocardial infarction in rodents. J Mol Cell Cardiol. 2010;49:771-80.

25. Roura S, Bago JR, Soler-Botija C, Pujal JM, Galvez-Monton C, Prat-Vidal C, Llucia-Valldeperas A, Blanco J, Bayes-Genis A. Human umbilical cord 
blood-derived mesenchymal stem cells promote vascular growth in vivo. PLoS ONE. 2012;7:e49447.

26. Gaafar TM, Abdel Rahman HA, Attia W, Hamza HS, Brockmeier K, El Hawary RE. Comparative characteristics of endothelial-like cells derived from human adipose mesenchymal stem cells and umbilical cord bloodderived endothelial cells. Clin Exp Med. 2014;14:177-84.

27. Cannella V, Piccione G, Altomare R, Marino A, Di Marco P, Russotto L, Di Bella S, Purpari G, Gucciardi F, Cassata G, et al. Differentiation and characterization of rat adipose tissue mesenchymal stem cells into endotheliallike cells. Anat Histol Embryol. 2018:47:11-20.

28. Cuccuini W, Poitevin S, Poitevin G, Dignat-George F, Cornillet-Lefebvre P, Sabatier F, Nguyen P. Tissue factor up-regulation in proinflammatory conditions confers thrombin generation capacity to endothelial colonyforming cells without influencing non-coagulant properties in vitro. J Thromb Haemost. 2010;8:2042-52.

29. Gremmels H, Teraa M, Quax PH, den Ouden K, Fledderus JO, Verhaar MC. Neovascularization capacity of mesenchymal stromal cells from critical limb ischemia patients is equivalent to healthy controls. Mol Ther. 2014;22:1960-70.

30. Limbourg A, KorffT, Napp LC, Schaper W, Drexler H, Limbourg FP. Evaluation of postnatal arteriogenesis and angiogenesis in a mouse model of hind-limb ischemia. Nat Protoc. 2009:4:1737-46.

31. Brenes RA, Jadlowiec CC, Bear M, Hashim P, Protack CD, Li X, Lv W, Collins MJ, Dardik A. Toward a mouse model of hind limb ischemia to test therapeutic angiogenesis. J Vasc Surg. 2012;56:1669-79 (discussion 1679).

32. Choi M, Lee HS, Naidansaren P, Kim HK, Eunju O, Cha JH, Ahn HY, Yang PI, Shin JC, Joe YA. Proangiogenic features of Wharton's jelly-derived mesenchymal stromal/stem cells and their ability to form functional vessels. Int J Biochem Cell Biol. 2013:45:560-70.

33. Reis PE, de Carvalho LP, Yasumura E, da Silva FH, Garcia BC, Beutel A, Sacramento CB, Baptista-Silva JC, de Campos RR, Takiya CM, et al. Impact of angiogenic therapy in the treatment of critical lower limb ischemia in an animal model. Vasc Endovasc Surg. 2014;48:207-16.

34. Cadot B, Gache V, Gomes ER. Moving and positioning the nucleus in skeletal muscle—one step at a time. Nucleus. 2015;6:373-81.

35. Roman W, Gomes ER. Nuclear positioning in skeletal muscle. Semin Cell Dev Biol. 2018;82:51-6.

36. Smadja DM, d'Audigier C, Guerin CL, Mauge L, Dizier B, Silvestre JS, Dal Cortivo L, Gaussem P, Emmerich J. Angiogenic potential of BM MSCs derived from patients with critical leg ischemia. Bone Marrow Transplant. 2012;47:997-1000.

37. Wang C, Li Y, Yang M, Zou Y, Liu H, Liang Z, Yin Y, Niu G, Yan Z, Zhang B. Efficient differentiation of bone marrow mesenchymal stem cells into endothelial cells in vitro. Eur J Vasc Endovasc Surg. 2018;55:257-65.

38. Oswald J, Boxberger S, Jorgensen B, Feldmann S, Ehninger G, Bornhauser $M$, Werner $C$. Mesenchymal stem cells can be differentiated into endothelial cells in vitro. Stem Cells. 2004;22:377-84.

39. Tancharoen W, Aungsuchawan S, Pothacharoen P, Markmee R, Narakornsak S, Kieodee J, Boonma N, Tasuya W. Differentiation of mesenchymal stem cells from human amniotic fluid to vascular endothelial cells. Acta Histochem. 2017:119:113-21.

40. Janeczek Portalska K, Leferink A, Groen N, Fernandes H, Moroni L, van Blitterswijk C, de Boer J. Endothelial differentiation of mesenchymal stromal cells. PLoS ONE. 2012;7:e46842.

41. Policha A, Zhang P, Chang L, Lamb K, Tulenko T, DiMuzio P. Endothelial differentiation of diabetic adipose-derived stem cells. J Surg Res. 2014;192:656-63.

42. Chen L, Xu Y, Zhao J, Zhang Z, Yang R, Xie J, Liu X, Qi S. Conditioned medium from hypoxic bone marrow-derived mesenchymal stem cells enhances wound healing in mice. PLoS ONE. 2014;9:e96161.

43. Teo GS, Ankrum JA, Martinelli R, Boetto SE, Simms K, Sciuto TE, Dvorak AM, Karp JM, Carman CV. Mesenchymal stem cells transmigrate between and directly through tumor necrosis factor-alpha-activated endothelial cells via both leukocyte-like and novel mechanisms. Stem Cells. 2012;30:2472-86.

44. Belmadani S, Matrougui K, Kolz C, Pung YF, Palen D, Prockop DJ, Chilian WM. Amplification of coronary arteriogenic capacity of multipotent stromal cells by epidermal growth factor. Arterioscler Thromb Vasc Biol. 2009;29:802-8.

45. Goedecke A, Wobus M, Krech M, Munch N, Richter K, Holig K, Bornhauser M. Differential effect of platelet-rich plasma and fetal calf serum on bone marrow-derived human mesenchymal stromal cells expanded in vitro. J Tissue Eng Regen Med. 2011;5:648-54.

46. Harris LJ, Zhang P, Abdollahi H, Tarola NA, DiMatteo C, Mcllhenny SE, Tulenko TN, DiMuzio PJ. Availability of adipose-derived stem cells in patients undergoing vascular surgical procedures. J Surg Res. 2010;163:e105-12.

47. Simons M, Alitalo K, Annex BH, Augustin HG, Beam C, Berk BC, Byzova T, Carmeliet P, Chilian W, Cooke JP, et al. State-of-the-art methods for evaluation of angiogenesis and tissue vascularization: a scientific statement from the American Heart Association. Circ Res. 2015;1 16:e99-132.

48. Iwase T, Nagaya N, Fujii T, Itoh T, Murakami S, Matsumoto T, Kangawa K, Kitamura S. Comparison of angiogenic potency between mesenchymal stem cells and mononuclear cells in a rat model of hindlimb ischemia. Cardiovasc Res. 2005:66:543-51.

49. Morris AD, Dalal S, Li H, Brewster LP. Human diabetic mesenchymal stem cells from peripheral arterial disease patients promote angiogenesis through unique secretome signatures. Surgery. 2018;163:870-6.

50. Brewster L, Robinson S, Wang R, Griffiths S, Li H, Peister A, Copland I, McDevitt T. Expansion and angiogenic potential of mesenchymal stem cells from patients with critical limb ischemia. J Vasc Surg. 2017;65(826-838):e821.

51. Bergers $\mathrm{G}$, Song $\mathrm{S}$. The role of pericytes in blood-vessel formation and maintenance. Neuro Oncol. 2005;7:452-64.

52. van Royen N, Piek JJ, Schaper W, Fulton WF. A critical review of clinical arteriogenesis research. J Am Coll Cardiol. 2009;55:17-25.

53. Hakimzadeh $\mathrm{N}$, Verberne HJ, Siebes M, Piek JJ. The future of collateral artery research. Curr Cardiol Rev. 2014;10:73-86.

54. Hendrikx G, Voo S, Bauwens M, Post MJ, Mottaghy FM. SPECT and PET imaging of angiogenesis and arteriogenesis in pre-clinical models of myocardial ischemia and peripheral vascular disease. Eur J Nucl Med Mol Imaging. 2016;43:2433-47.

55. Beauchamp JR, Morgan JE, Pagel CN, Partridge TA. Dynamics of myoblast transplantation reveal a discrete minority of precursors with stem cell-like properties as the myogenic source. J Cell Biol. 1999;144:1113-22.

56. Lee RH, Pulin AA, Seo MJ, Kota DJ, Ylostalo J, Larson BL, Semprun-Prieto L, Delafontaine P, Prockop DJ. Intravenous hMSCs improve myocardial infarction in mice because cells embolized in lung are activated to secrete the anti-inflammatory protein TSG-6. Cell Stem Cell. 2009;5:54-63.

57. Koutakis P, Myers SA, Cluff K, Ha DM, Haynatzki G, McComb RD, Uchida K, Miserlis D, Papoutsi E, Johanning JM, et al. Abnormal myofiber morphology and limb dysfunction in claudication. J Surg Res. 2015;196:172-9.

58. Heemskerk AM, Strijkers GJ, Drost MR, van Bochove GS, Nicolay K. Skeletal muscle degeneration and regeneration after femoral artery ligation in mice: monitoring with diffusion MR imaging. Radiology. 2007;243:413-21.

59. Kim SW, Han H, Chae GT, Lee SH, Bo S, Yoon JH, Lee YS, Lee KS, Park HK, Kang KS. Successful stem cell therapy using umbilical cord blood-derived multipotent stem cells for Buerger's disease and ischemic limb disease animal model. Stem Cells. 2006;24:1620-6.

60. Dash NR, Dash SN, Routray P, Mohapatra S, Mohapatra PC. Targeting nonhealing ulcers of lower extremity in human through autologous bone marrow-derived mesenchymal stem cells. Rejuvenation Res. 2009;12:359-66.

61. Lasala GP, Silva JA, Gardner PA, Minguell JJ. Combination stem cell therapy for the treatment of severe limb ischemia: safety and efficacy analysis. Angiology. 2010;61:551-6.

62. Powell RJ, Marston WA, Berceli SA, Guzman R, Henry TD, Longcore AT, Stern TP, Watling S, Bartel RL. Cellular therapy with Ixmyelocel-T to treat critical limb ischemia: the randomized, double-blind, placebo-controlled RESTORE-CLI trial. Mol Ther. 2012;20:1280-6.

63. Lasala GP, Silva JA, Minguell JJ. Therapeutic angiogenesis in patients with severe limb ischemia by transplantation of a combination stem cell product. J Thorac Cardiovasc Surg. 2012;144:377-82.

64. Lee HC, An SG, Lee HW, Park JS, Cha KS, Hong TJ, Park JH, Lee SY, Kim SP, Kim YD, et al. Safety and effect of adipose tissue-derived stem cell implantation in patients with critical limb ischemia: a pilot study. Circ J. 2012;76:1750-60.

65. Das AK, Bin Abdullah BJ, Dhillon SS, Vijanari A, Anoop CH, Gupta PK. Intra-arterial allogeneic mesenchymal stem cells for critical limb ischemia are safe and efficacious: report of a phase I study. World J Surg. 2013;37:915-22. 
66. Yang SS, Kim NR, Park KB, Do YS, Roh K, Kang KS, Kim DI. A phase I study of human cord blood-derived mesenchymal stem cell therapy in patients with peripheral arterial occlusive disease. Int J Stem Cells. 2013;6:37-44.

67. Powell RJ, Comerota AJ, Berceli SA, Guzman R, Henry TD, Tzeng E, Velazquez O, Marston WA, Bartel RL, Longcore A, et al. Interim analysis results from the RESTORE-CLI, a randomized, double-blind multicenter phase II trial comparing expanded autologous bone marrow-derived tissue repair cells and placebo in patients with critical limb ischemia. J Vasc Surg. 2011:54:1032-41.

68. El Omar R, Xiong Y, Dostert G, Louis H, Gentils M, Menu P, Stoltz JF, Velot $\mathrm{E}$, Decot $\mathrm{V}$. Immunomodulation of endothelial differentiated mesenchymal stromal cells: impact on T and NK cells. Immunol Cell Biol. 2016:94:342-56
69. Seo Y, Kim HS, Hong IS. Stem cell-derived extracellular vesicles as immunomodulatory therapeutics. Stem Cells Int. 2019;2019:5126156.

70. Phelps J, Sanati-Nezhad A, Ungrin M, Duncan NA, Sen A. Bioprocessing of mesenchymal stem cells and their derivatives: toward cell-free therapeutics. Stem Cells Int. 2018;2018:9415367.

\section{Publisher's Note}

Springer Nature remains neutral with regard to jurisdictional claims in published maps and institutional affiliations.
Ready to submit your research? Choose BMC and benefit from:

- fast, convenient online submission

- thorough peer review by experienced researchers in your field

- rapid publication on acceptance

- support for research data, including large and complex data types

- gold Open Access which fosters wider collaboration and increased citations

- maximum visibility for your research: over $100 \mathrm{M}$ website views per year

At BMC, research is always in progress.

Learn more biomedcentral.com/submissions 